\title{
CONTRIBUTION A L'ÉTUDE HISTOLOGIQUE ET ULTRASRUCTURALE DES GLANDES MANDIBULAIRES ET ANNEXES DE QUELQUES ANTHOPHORIDAE ${ }^{(1)}$
}

\author{
Beitrag zum Studium der Histologie \\ und des Feinbaues der Mandibulardrïsen \\ und ihrer Anhänge bei einigen Anthophoridae
}

\author{
Yvonne HEROIN et François RAMADE \\ avec la collaboration technique de Murielle Picard et Pierre Vallée \\ Laboratoire de Zoologie, Faculté des Sciences, 91 - Orsay \\ Laboratoire de Recherches de la Chaire de Zoologie, \\ Institut national agronomique, 16, rue Claude-Bernard, 75 - Paris (5e) \\ Institut national de la Recherche agronomique
}

\begin{abstract}
SUMMARY
A CONTRIBUTION TO THE HISTOLOGICAL AND ULTRASTRUCTURAL STUDY OF THE MANDIBULAR GLANDS AND APPENDAGES OF SOME "ANTHOPHORIDAE»
\end{abstract}

A study of the mandibular glands of Eucera longicornis Scop. and Anthophora acervorum Lat. has revealed important histological and ultrastructural differences between the two species, such as several individual variations in the glandular cells.

The very polymorphous nucleus sometimes appears in the form of a crescent; its shape is more irregular in Eucera than in the other species studied. The cytoplasm of the perinuclear region has a strong basophily together with a great wealth of ribo-nucleins, as is shown by the classic Unna's test, using methyl Green pyronin combined with ribonuclease. In the cavity of the nuclei we can observe a pyroninophile juxtanuclear zone richer in RNA than remaining cytoplasm. With an

(1) Ce travail a été réalisé à la Station de Recherches sur l'Abeille et les Insecies sociaux, 91 Bures-sur-Yvette, Institut national de la Recherche agronomique. 
electron microscope it can be observed that it is an extranuclear formation consisting of the collection of a great many Palade's granules and numerous ergastoplasmic saccules.

In Eucera the glandular cells can be divided in two classes according to the fine structure of the nucleus, the ergastoplasm and the various vacuolar or lysosomial inclusions contained in the cytoplasm. These two ultrastructural types have not been found together in the same gland, of which all the secretory elements always possess a great cytological similarity; if, however, several organs take $n$ from a number of individual insects are examined, one will find all the intermediate stages between the two extremes.

In Anthophora the more extensive mitochondria shows important ultrastructural variations in regard to the elaboration of the secretory vacuoles. They are more numerous at maturity and larger in size than the homologous recesses in Eucera.

\section{RESUME}

L'étude des glandes mandibulaires d'Eucera longicornis Scop et d'Anthophora acervorum Lat. a révélé d'importantes différences histologiques et ultrastructurales entre ces deux espèces ainsi que diverses variations individuelles des cellules glandulaires.

Leur noyau, très polymorphe, revêt parfois un aspect "en croissant ", sa forme est plus irrégulière chez Eucera que dans l'autre espèce étudiée. Le cytoplasme de la région périnucléaire possède une forte basophilie liée à une grande richesse en ribonucléines ainsi qu'en atteste le test classique de Unna au Vert de méthyle-pyronine combiné à l'usage de la ribonucléase. On remarque dans la cavité des noyaux une zone juxtanucléaire pyroninophile plus riche en ARN que le reste du cytoplasme. La microscopie électronique permet de démontrer qu'il s'agit d'une formation extra-nucléaire constituée par le rassemblement d'une grande quantité de grains de Palade et de nombreuses saccules ergastoplasmiques.

Chez Eucera, les cellules glandulaires peuvent être classées en deux catégories selon la structure fine de leur noyau, de leur ergastoplasme et de diverses inclusions vacuolaires ou lysosomiales que renferme le cytoplasme. Ces deux types ultrastructuraux n'ont pas été rencontrés simultanément dans une même glande dont tous tes éléments sécréteurs présentent toujours une grande similitude cytologique; mais si l'on compare entre eux plusieurs organes prélevés chez des insectes distincts, on peut observer tous les intermédiaires entre ces deux types extrêmes.

Chez Anthophara, le chondriome, plus abondant, présente d'importantes variations ultrastructurales en rapport avec l'élaboration des vacuoles sécrétoires. Celles-ci sont plus nombreuses à maturité et de tailłe supérieure aux enclaves homologues d'Eucera.

\section{I. - INTRODUCTION}

L'histologie des glandes mandibulaires des Apoidea a fait l'objet de divers travaux, parfois fort anciens (Schiemenz, 1883; Bordas, 1894; Heselhaus, 1922; Kratky, 1931; Altenkirch, 1962 et Nedel, 1960). Stein (1962) a décrit l'ultrastructure de ces organes chez Bombus terrestris L. Plus récemment, LANDiM (1968) a étudié la structure fine des glandes salivaires céphaliques et thoraciques chez divers Apoidea (Melipona, Xylocopa, Megachile et Colletes), mais ces organes sont morphologiquement et physiologiquement assez différents des glandes mandibulaires.

Certes, Schiemenz, dès 1883, décrivait dans un important mémoire l'anatomie microscopique de la plupart des familles d'Apoidea, mais bien des points restent encore à préciser quant à l'histologie et l'histochimie de ces organes. D'autre 
part, leur ultrastructure est mal connue et la publication de STEIN (1962) soulève bien des problèmes en ce qui concerne le rôle des différentes inclusions cytoplasmiques observées au cours des stades successifs du cycle sécrétoire. Aussi nous a-t-il semblé utile de reprendre ces investigations sur des Anthophoridae essentiellement Eucera longicornis Scop. et Anthophora acervorum Latr. Ces deux espèces d'Apoidea, aux mœurs solitaires, sont assez communes dans la région parisienne au cours du printemps bien que nous ayons eu quelques difficultés à nous procurer un nombre suffisant d'individus pour effectuer nos recherches.

A. acervorum est une espèce précoce qui nidifie selon un plan plus ou moins horizontal dans les vieux murs et les talus, le plus souvent en aménageant un trou préexistant. Au fond de la galerie sont construites des cellules composées d'un substrat amalgamé au moyen, semble-t-il, d'une sécrétion protéique et d'une membrane cireuse. La ponte, échelonnée pendant plus d'un mois s'effectue dans ces structures cellulaires; la même femelle peut édifier plusieurs nids.

$E$. longicornis, plus tardive, construit son nid dans le sol en forant un tunnel vertical dans une surface plane. Celui-ci donne accès à des galeries horizontales se terminant par des cellules. Les parois de ces constructions semblent également consolidées à l'aide de sécrétions.

Il existe de nombreuses observations sur le comportement nidificateur de ces espèces dans la nature, mais il est également possible de les faire nidifier en captivité ce qui permet des études plus précises (Lecomte, non publié). Aussi envisageons-nous, lors de recherches ultérieures, d'établir les corrélations éventuelles entre le cycle évolutif de ces insectes et les transformations cytologiques et nucléaires des cellules sécrétrices de la glande mandibulaire.

Par ailleurs, il semble que ces glandes puissent jouer chez les $A n$. phoridae un rôle différent de celui qui leur est dévolu chez les Bombidae.

En effet, dans le genre Bombus, elles élaborent une phérormone vc atile avec laquelle les mâles marquent leur territoire et dont les femelles perçoivent aussi l'odeur.

Chez Eucera et Anthophora, les sécrétions des giandes mandibulaires sont peut-être en rapport avec l'activité nidificatrice. L'un d'entre nous (Y. Herorn, 1966) a d'ailleurs pu préciser à l'aide d'éléments marqués, chez une espèce d'Apoidea : Osmia cornuta Lat. appartenant à une famille voisine, l'existence d'une sécrétion intervenant dans l'assemblage des matériaux constitutifs du nid. Ce fait n'exclut pas que ces glandes puissent aussi jouer un rôle dans le rapport des sexes.

\section{II. - MATÉRIEL ET MÉTHOdES}

Les Eucera ont été prises dans la nature à des époques diverses de la période de nidification s'échelonnant du début juin au début juillet; les Anthophora utilisées pour l'histologie ordinaire apparaissent plus précocement mais celles dont l'ultrastructure a été étudiée dans cette note furent capturées le 14 mai 1968 et fixées le lendemain.

Pour l'histologie ordinaire, les insectes ont été, dès leur capture, mis à $4^{\circ}$ pendant environ une heure, afin de les endormir, puis disséqués rapidement soit dans le Ringer, soit directement dans le fixateur (Carnoy, Bouin ou alcool 95\%). Les temps de fixation ont varié selon les colorations utilisées. Les coupes ont été faites à $5 \mu$. Les préparations ont été colorées à l'hémalunéosine pour les études topographiques générales. Les ribonucléines ont été détectées par les réactions au bleu de toluidine tamponné, au Feulgen et par le test de Unna-Pappenheim. Celui-ci a été pratiqué selon la technique 
de l'Institut d'Histochimie médicale de la Faculté de Médecine de Paris. Après fixation à l'alcool 95º, les coupes sont placées dans le vert de méthyle-pyronine pendant trente minutes à $45^{\circ}$ après passage dans un tampon acide acétique-acétate de sodium $0,2 \mathrm{M}$. Après observations et photographie, une coupe contiguë à la précédente est digérée à la RNase pendant deux heures à $37^{\circ} \mathrm{C}$ pour vérifier la spécificité de la réaction.

Pour les études ultrastructurales, les têtes furent disséquées directement dans le mélange fixateur. Quelques fixations furent réalisées à l'acide osmique à 1 p. 100 tamponné au tampon phosphate de Millonig $(0,2 \mathrm{M})$ au $\mathrm{pH} 7,4$.

La plupart des glandes furent fixées à $4{ }^{\circ} \mathrm{C}$ pendant deux heures dans une solution de glutaraldéhyde à 3,5 p. 100 tamponné dans du cacodylate de sodium $0,05 \mathrm{M}$ additionné de $\mathrm{ClH}$ qs pour obtenir un $\mathrm{pH} 7,4$ et de saccharose $0,2 \mathrm{M}$ puis post-fixées une heure à la température ordinaire dans l'acide osmique à 1 p. 100 dilué dans le même tampon.

Après déshydratation dans les alcools et passage à l'oxyde de propylène, les pièces ont été inclues à l'Epon.

Les coupes ultrafines ont été réalisées à l'ultramicrotome Reichert OMU II, contrastées à l'acétate d'Urane en solution saturée dans l'alcool à $50^{\circ} \mathrm{B}$ pendant trente à quarante minutes à la température ordinaire puis à l'acétate de plomb selon Reynold. L'examen des préparations et les clichés ont été réalisés avec le microscope électronique Hitachi HS 7 du Laboratoire de Zoologie de l'Institut national agronomique.

\section{III. - HISTOLOGIE DE LA GLANDE MANDIBULAIRE ET DE SES ANNEXES}

Les glandes mandibulaires d'Eucera longicornis se présentent sous la forme de deux masses sacciformes blanchâtres situées profondément dans la capsule céphalique et très nettement séparées de la mandibule à laquelle elles sont reliées par un canal excréteur assez contourné. A l'opposé de ce que nous avons observé chez Anthophora, elles sont bien distinctes du réservoir. Ces glandes sont entourées par une masse de tissu adipeux dont l'importance semble varier avec l'état physiologique de l'insecte. Leur pigmentation jaune orangé présente une intensité assez variable selon l'âge des individus. Le réservoir revêt l'aspect d'une poche mince déformable et indépendante qui paraît déboucher dans la mandibule par une formation chitineuse (fig. $1, n^{\circ} 1$ ).

Chez Anthophora, le réservoir semble au contraire étroitement accolé à la partie sécrétrice des glandes mandibulaires et débouche plus centralement dans la mandibule (fig. 1, $n^{\circ}$ 2).

\section{A. - Anatomie microscopique et histologie de la glande mandibulaire d'Eucera}

Elle se présente comme un sac formé par une rangée de cellules grossièrement quadrangulaires, juxtaposées les unes aux autres.

Des canalicules intracellulaires partent, semble-t-il, d'une zone péri-nucléaire et draineraient le cytoplasme, ils se réunissent d'une façon très nette en un faisceau situé au centre de la couronne formée par les cellules sécrétrices. Ce faisceau débouche dans un canal excréteur commun qui se déverse dans le réservoir de la glande (pl. I, fig. 1 et 2).

Les cellules des canaux sécréteurs ont un aspect très aplati (pl. I, fig. 1 et 2), leur noyau ovoïde, de taille assez importante présente une réaction très fortement positive au Feulgen (pl. II, fig. 1) qui révèle une certaine concentration en ADN.

Les cellules $d u$ réservoir sont enveloppées par une membrane plasmique d'aspect sinueux et plissé. Ces cellules peuvent subir de fortes déformations sous 


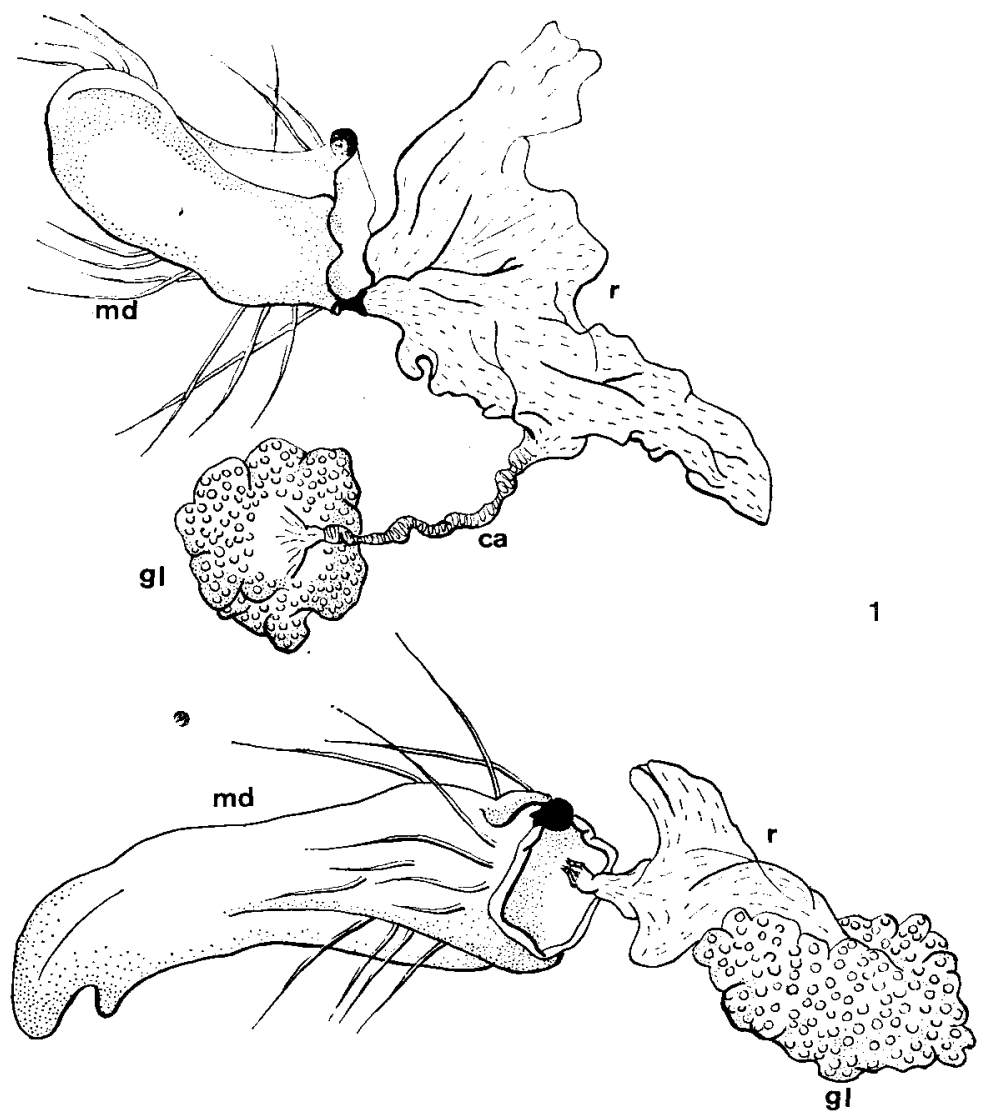

2

Fig. 1. - Schêma général des glandes mandibulaires chez Eucera (1) et Anthophora (2) avec leur réservoir (voir Mathewson A. sur Peponapis Pruinosa). La glande mandibulaire (gI) d'Anthophora entoure le réservoir (r) contrairement à Eucera dont la glande se jette dans le réservoir par un canal (ca).

Aвв. 1. - Allgemeines Schema der Mandibeldrüsen von Eucera (1) und Anthophora (2) mit Resevoir. (Siehe Mathewson A., über Peponapis Pruinosa.) Im Gegensatz zu Eucera, bei der aus der Drüse ein Kanal (ca) in das Reservoir führt, umschliesst bei Anthophora die Drüse das Reservoir (r).

l'effet de contraintes mécaniques, elles sont très souples et possèdent des noyaux de forme plus régulière que ceux des canaux excréteurs, dans lesquels la réaction de Feulgen met en évidence d'importants amas de chromatine.

Les cellules glandulaires paraissent peu nombreuses sur une coupe transversale de la glande et présentent des contours quadrangulaires et une grande taille. Les diverses colorations histologiques que nous avons pratiquées permettent de distinguer, dans le cytoplasme granuleux, des segments de canalicules contournés. Chez certains individus capturés en fin juin à Lusignan, nous avons observé, à la périphérie des cellules glandulaires typiques, des vacuoles sphériques assez importantes (pl. I, fig. 1). 
La zone cytoplasmique périnucléaire présente une texture assez claire, plus fine et plus homogène que les régions périphériques du cytoplasme glandulaire (pl. II, fig. 1 et 2). Le noyau, d'aspect croûteux, s'avère très polymorphe, cet aspect étant assez constant dans les diverses cellules d'une même glande (pl. I et II). Certains noyaux sont ovoïdes et plus colorés, d'autres présentent une forme en croissant plus ou moins accentuée dans la concavité duquel existe une substance de texture homogène et très chromophile; enfin, certaines cellules renferment un noyau aux contours plus irréguliers, vaguement quadrangulaires dont la surface se déprime en deux ou trois concavités du même type que celles du "croissant " précité (pl. II, fig. 2).

Après réaction de Feulgen, le noyau des cellules glandulaires est moins positif que celui des cellules des canaux excréteurs et du réservoir ce qui témoigne une plus faible concentration de l'ADN (pl. II, fig. 1).

Les variations de forme du noyau que nous observons dans les cellules glandulaires d'individus différents semblent en rapport avec l'activité sécrétoire des insectes (NEDEL, 1960).

A l'aide du test de Unna-Pappenheim au vert de méthyle-pyronine, nous avons constaté que les noyaux lobés mis en évidence par les diverses colorations utilisées, prennent intensément le vert de méthyle alors que la partie déprimée concave de la surface nucléaire renferme une zone pyroninophile de taille variable selon le plan de coupe, étroitement juxtaposée à la masse de chromatine nucléaire (pl. II, fig. 2 et 3 ).

Cette même zone se révèle optiquement vide après passage à la ribonucléase. Ceci tendrait à prouver que le noyau est constitué par une zone riche en ADN de densité variable avec l'état d'activité de la glande. Cette zone est si étroitement juxtaposée à un amas ribonucléique qu'il est difficile de préciser à l'aide des méthodes histologiques courantes si ce dernier représente un élément nucléaire - tel un nucléole géant par exemple — ou une inclusion cytoplasmique intimement accolée au noyau. C'est d'ailleurs dans le but de résoudre ce problème que fut initialement entreprise l'étude ultrastructurale de ces glandes.

Après coloration au bleu de toluidine tamponné au $\mathrm{pH} \mathrm{4,6}$ les cellules glandulaires présentent autour du noyau des plages basophiles plus denses que le reste du cytoplasme (pl. I, fig. 3 ).

Enfin, la réaction métachromatique pratiquée avec ce même colorant paraît négative.

\section{B. - Anatomie microscopique et histologie de la glande mandibulaire chez Anthophora acervorum}

Elles se présentent comme deux sacs étroitement liés aux réservoirs (pl. III, fig. 1). De même que chez Eucera, une seule rangée de cellules grossièrement rectangulaires entoure la section du réservoir dont la membrane plasmique est particulièrement plissée.

Le canalicule intracellulaire en contact très étroit avec le noyau est enroulé en spirale autour de ce dernier et les microvilli sont très apparents dans la partie périnucléaire (fig. 2). Le trajet intracytoplasmique devient, ensuite, rectiligne pour finalement s'enrouler sur lui-même à la partie distale de la cellule. Il forme ainsi un enchevêtrement très serré, grossièrement sphérique, au centre duquel 
on peut observer une lumière parfaitement circulaire et débouche isolément dans le réservoir (pl. III).

L'étude histologique d'Anthophora n'a pas été aussi détaillée que celle d'Eucera mais on peut cependant remarquer que, dans un cytoplasme granuleux, les noyaux présentent des formes très différentes, en croissant et surtout multilobées. Leur volume paraît important et comme chez Eucera leur concentration en nucléine est assez faible bien que l'on remarque de place en place des grains de chromatine de plus forte densité (pl. III, fig. 1).

De petits canaux excréteurs extracellulaires semblent déboucher directement dans le réservoir médian.

D'autre part, la glande paraît, sur certaines coupes, partiellement coiffée par un ensemble de petites cellules au cytoplasme vacuolisé et de texture plus hétérogène que celui des cellules glandulaires typiques (pl. III, fig. 1). Il est probable qu'il s'agit d'une subdivision de la glande mandibulaire mais d'autres recherches s'imposent pour préciser la fonction de cette catégorie cellulaire.

\section{IV. - ULTRASTRUCTURE DES GLANDES MANDIBULAIRES}

L'aspect général des glandes mandibulaires examinées en microscopie électronique est semblable chez Eucera et Anthophora. Elles présentent une structure alvéolaire avec une nette individualisation des cellules sécrétrices. Celles-ci possèdent des contours réguliers, subsphériques et elles sont souvent séparées les unes des autres par un espace lacunaire plus ou moins important. Cependant, cette individualisation des cellules n'est pas systématique et l'on peut observer dans certains cas une contiguité entre plusieurs éléments voisins. La partie périphérique de la glande est recouverte d'une membrane conjonctive anhiste et l'on remarque dans l'espace intercellulaire de nombreuses trachéoles disposées de façon ramifiée. Le noyau occupe une position centrale et sa forme varie beaucoup selon le stade d'activité de la glande.

Le cytoplasme se caractérise par sa richesse en diverses enclaves polymorphes, parmi lesquelles on remarque des vacuoles renfermant le produit de sécrétion. On observe aussi sur les coupes diverses sections transversales ou obliques du canal collecteur intracytoplasmique qui draine le matériel sécrété par la cellule glandulaire.

\section{A. - Eucera}

\section{1. - Ultrastructure des glandes mandibulaires d'Eucera.}

Les membranes cellulaires. L'ensemble de la glande est entouré par une tunica propria dont l'épaisseur est comprise entre 3000 et $5000 \AA$. Cette membrane présente une structure hétérogène et semble constituée par un ensemble de feuillets fibrillaires empilés, réunis par une substance fondamentale amorphe. La tunica propria présente par places un espacement de ses feuillets, par rapport aux membranes cellulaires sous-jacentes, dans lequel s'insinuent des diverticules trachéolaires (pl. VI, fig. 2).

Selon Low (1962), cette tunica propria peut être assimilée à une membrane 
basale. Les cellules sécrétrices sont souvent séparées par des espaces lacunaires par suite de la texture lâche de la glande. La tunica propria recouvre alors une partie importante de leur surface mais elle en demeure séparée par la membrane plasmique, qui représente la véritable enveloppe cellulaire alors que la tunica propria est un élément extracellulaire.

Dans les régions de la glande où les cellules sécrétrices présentent une plus forte densité, les membranes plasmiques peuvent être au contraire en étroite contiguité; on observe alors par place des zones de jonction entre les membranes plasmiques de deux cellules voisines qui représentent des maculae adhaerens, c'est-à-dire des desmosomes au sens défini par Farquhar et PALAdE $(1963,1965)$ et KeLLY (1966).

La membrane plasmique présente de nombreux replis et invaginations, profondes de 1 à $2 \mu$, dont la signification fonctionnelle semble liée à l'accroissement de la surface d'échange entre la cellule glandulaire et le milieu intérieur. Ces étroits espaces compris entre les replis de la membrane plasmique sont transparents aux électrons et baignés par le liquide interstitiel qui remplit toutes les régions lacunaires péricellulaires (pl. VI, fig. 2).

\section{2. - Ultrastructure du cytoplasme.}

\section{a. Les formations ergastoplasmiques.}

La forte basophilie cytoplasmique et l'intense pyroninophilie mises en évidence en histologie classique résultent de la grande richesse du cytoplasme en formations ergastoplasmiques. Celui-ci est réellement envahi par une multitude de grains de Palade et par de nombreuses cisternae ergastoplasmiques du reticulum endoplasmique granulaire.

L'ergastoplasme présente des aspects variés en rapport avec l'état d'activité glandulaire. Il est toujours plus abondant dans la région cytoplasmique périnucléaire. En particulier, la structure très riche en ribonucléines décelable dans la concavité des lobes nucléaires résulte de l'accumulation de telles formations ergastoplasmiques à proximité du noyau.

La microscopie électronique permet d'apporter une réponse catégorique à ce problème d'une formation nucléolaire ou cytoplasmique très basophile observable dans la région juxtanucléaire en histologie classique : il s'agit du rassemblement à proximité du noyau d'une grande quantité de matériel ergastoplasmique et de ribosomes et non pas d'un nucléole, la formation observée étant de nature extranucléaire (pl. IV, fig. 1).

Un autre fait important caractérise l'ultrastructure cytoplasmique de certaines cellules glandulaires : les cisternae ergastoplasmiques ne sont pas isolées, dispersées dans le hyaloplasme, mais au contraire réunies en amas parfois importants de feuillets parallèles ou plus généralement disposés en spires ou de façon concentriqu'; (pl. IV, fig. 1 et pl. V). Scharrer (1962), qui semble avoir signalé pour la première fois de telles dispositions chez les insectes, les a dénommées "spires ergastoplasmiques "dans son étude ultrastructurale sur les corpora allata de Leucophaea maderae. Depuis, d'autres auteurs, en particulier Joly et al. (1968) ont décrit des formations analogues dans ces mêmes organes chez divers insectes et Beaulaton (1968) en a aussi observées dans la glande prothoracique d'Antheraea pernyi (L.). Enfin, en ce qui concerne des cellules à sécrétion exocrine, STAU- 
BLI et al. (1966) remarquent des amas spiraliformes de nature ergastoplasmique dans les cellules épithéliales de l'intestin moyen d'Aedes.

Chez Eucera, les rassemblements de Cisternae ergastoplasmiques comprennent en général un plus faible nombre d'éléments (3 à 8$)$ que dans les autres espèces. Les feuillets sont disposés de façon concentrique ou sinueuse et empilés parallèlement ou parfois enroulés en spirale. Il existe un nombre important de telles formations dispersées dans tout le cytoplasme.

STEIN (1962) observe des dispositions analogues du reticulum endoplasmique dans les glandes mandibulaires de Bombus, mais elles comportent un très grand nombre de cisternae juxtaposées, à la différence de ce que nous observons chez Eucera.

Il convient toutefois de préciser que ces dispositions particulières de l'ergastoplasme ne s'observent qu'à certaines périodes de l'activité glandulaire alors qu'aux autres stades, le reticulum endoplasmique granulaire est au contraire dispersé sous forme de cisternae isolées dans l'ensemble du cytoplasme (pl. IV, fig. 2).

b. Le Chondriome est très développé dans l'ensemble des cellules que nous avons pu examiner quel que soit leur état d'activité.

Il existe deux types de mitochondries : le premier est constitué par des organites de forme classique, plus longs que larges, de section transversale subcirculaire, n'excèdant pas $5000 \AA$ pour une longueur en général comprise entre 1 et $2 \mu$. Le second est atypique. Il s'agit d'éléments proportionnellement plus courts que les précédents, ils atteignent jusqu'à $3,5 \mu$ de longueur et $1,3 \mu$ de large. Leurs contours sont moins réguliers, parfois triangulaires ou subquadrangulaires (pl. VI, fig. 2). Ils possèdent des cristae disposées de façon irrégulière : certaines régions de la mitochondrie renferment des crêtes disposées en feuillets plans et parallèles alors que dans d'autres, elles présentent une disposition en arc de cercle, voire cylindrique. On remarque aussi dans certaines mitochondries des cristae tubulaires, mais leur présence n'est pas constante. STEIN (1962) a fait aussi une telle observation dans les glandes mandibulaires de Bombus. Par ailleurs, une partie du contenu de la matrice mitochondriale est peu dense aux électrons et dépourvu de cristae. Nous avons constaté dans certains cas que les parois externes des mitochondries de ce type s'invaginent et paraissent alors englober une portion du cytoplasme environnant. On peut cependant envisager une interprétation opposée de telles images, ces figures pourraient aussi représenter une phase d'expulsion de sécrétions mitochondriales. L'ensemble des caractères ultrastructuraux de ce second type de mitochondries nous conduit à envisager de les assimiler aux éléments décrits par Beaulaton (1964) sous le terme de " macromitochondries " dans les cellules glandulaires prothoraciques d'Antheraea pernyi.

c. L'appareil de Golgi est atypique dans les cellules glandulaires. Il comporte deux ou trois cisternae disposées parallèlement, associées à quelques vésicules et à de nombreuses vacuoles transparentes aux électrons.

De telles formations existent aussi dans les cellules homologues de Bombus et sont parfaitement observables sur les clichés publiés par STEIN (1962), bien que cet auteur ne semble pas les avoir identifiés à des dérivés golgiens dans sa publication. Le cytoplasme des cellules glandulaires est aussi parcouru par une multitude de microtubules, lesquelles sont fort apparentes dans la région périnucléaire (pl. V). 
d. Les enclaves cytoplasmiques de nature sécrétoire.

Les glandes mandibulaires se caractérisent par la grande abondance d'inclusions cytoplasmiques que l'on peut observer à l'intérieur des cellules sécrétrices. Cette remarquable densité en enclaves diverses se rapporte sans aucun doute aux diverses phases de l'élaboration de la substance sécrétée par les cellules glandulaires.

Les produits de l'activité glandulaire se présentent au niveau ultrastructural sous un aspect figuré extrêmement polymorphe. La grande variété de taille et de structure de ces inclusions cytoplasmiques complique beaucoup l'analyse des différentes étapes du cycle sécrétoire. Nous distinguerons cinq catégories distinctes, qui ne représentent à notre avis que des stades repères dans les diverses phases de l'activité glandulaire, des formes de transition s'observant en effet entre la plupart d'entre elles. Ce sont :

Type $I$ : des vésicules et des vacuoles subsphériques, de petite taille (de $1500 \AA$ à $1 \mu$ ) parfois isolées mais plus souvent rassemblées par groupe de 5 unités ou plus et disposées en arc de cercle, dont le contenu ne semble pas préservé par la fixation et qui paraissent de ce fait optiquement vides (pl. IV, fig. 2). Ces formations ont vraisemblablement une origine golgienne.

Type $I I$ : de grandes vacuoles (de 1 à $4 \mu$ ) au contenu granulaire et de densité moyenne aux électrons, qui parait de répartition homogène. On observe parfois à l'intérieur de ces dernières une ou deux inclusions opaques aux électrons. Ces grandes vacuoles se rencontrent dans tout le cytoplasme, mais paraissent plus fréquentes au voisinage du canal collecteur de la cellule glandulaire, ce qui suggèrerait qu'elles correspondent à la phase ultime de l'élaboration du matériel sécrétoire. Les plus petites d'entre elles possèdent des contours subsphériques alors que les autres présentent des limites irrégulières.

Type III : des corps lamellaires, dont certains semblent dériver du type précédent. Ils se caractérisent par un contenu granulaire fortement hétérogène avec des plages moins transparentes aux électrons. Sur les parois de ces derniers apparaissent des formations très denses, lamellaires empilées en feuillets qui se dissocient ultérieurement en une série de lamelles empilées les unes sur les autres (pl. V).

Type $I V$ : des corps denses intracytoplasmiques, de faible taille, opaques aux électrons. Ces derniers mesurent de 2000 à $5000 \AA$, rarement plus. Sur certaines micrographies, ils paraissent entourés d'une paroi capsulaire. Ces corps denses prennent naissance dans le cytoplasme (pl. IV, fig. 1 et pl. V) sans aucun rapport précis avec le Golgi ou l'ergastoplasme. StEIN (1962) les a observé chez Bombus et les dénomme "Prosekretgranula ", il fait de ces structures la forme figurée initiale du cycle sécrétoire. Cela ne paraît pas évident sur nos propres clichés, car nous n'observons pas de forme de transition bien nette entre ces inclusions et les grandes vacuoles sécrétoires (type II).

Type $V$ : des corps de structure membraneuse de nature probablement lysosomiale se présentent sous l'aspect de grandes vacuoles, transparentes aux électrons (pl. VI), dans lesquelles on remarque la présence d'une inclusion très dense dans son ensemble bien que de structure hétérogène. De plus, ces vacuoles renferment des systèmes complexes de membranes disposées en feuillets parallèles ou empilées concentriquement.

On a décrit de telles ultrastructures dans de nombreux tissus d'insectes. 
Ainsi, dans les glandes répugnatoires de Pyrrhocoris apterus, STEIN (1966) a observé des inclusions cytoplasmiques d'aspect très voisin des corps membranaires que nous décrivons chez Eucera (type V), et qu'il identifie à des cytolysomes. SCHARRER (1966) décrit aussi de telles formations dans la glande prothoracique en dégénérescence de Leucophaea maderae qu'elle homologue à des structures lysosomiales.

Chez Eucera, la taille de ces inclusions membranaires semble plus faible que celle décrite chez Bombus par Stein; dans notre matériel, elles mesurent de 1 à $3 \mu$ et présentent souvent des contours parfaitement circulaires (pl. VI).

\section{3. - Ultrastructure nucléaire.}

L'aspect du noyau, très variable, est en étroite relation avec les divers stades d'activité sécrétoire. Rappelons que NEDEL (1960) observe sur des préparations histologiques ordinaires de fortes modifications dans la forme et la taille du noyau dans les vingt minutes qui suivent l'expulsion du sécrétat dans les glandes mandibulaires de Trigona. Nous distinguons deux types extrêmes dans la morphologie nucléaire. Certaines glandes renferment des noyaux aux contours réguliers, avec une surface lisse, dont la forme est subovoïde. Dans d'autres, au contraire, la surface nucléaire est extrêmement plissée et le noyau possède un aspect multilobé avec de profondes échancrures séparant les divers lobes (pl. IV). On rencontre toutes les formes intermédiaires entre ces deux types extrêmes.

La membrane nucléaire est toujours mince, régulière et pourvue de nombreux pores très apparents sur les coupes tangentielles à sa surface. On remarque à l'intérieur du noyau de nombreux blocs granulaires très denses aux électrons et dispersés dans toute sa masse, qui correspondent aux nombreux amas de chromatine mis en évidence par la réaction de Feulgen dans les préparations histologiques, et d'autres inclusions de structure hétérogène, avec des zones granulaires dispersées en réseau dans les mailles duquel est enfermé un matériel de faible densité électronique.

\section{B. - Anthophora.}

Il existe un certain nombre de différences histologiques et ultrastructurales entre les cellules des glandes mandibulaires d'Eucera et d'Anthophora. Chez ces dernières, le noyau a une forme plus régulière. Il possède, certes, des replis de sa membrane (pl. VIII, fig. 1) et parfois même présente un aspect profondément échancré, sans jamais atteindre toutefois la forme multilobulaire très fréquente chez Eucera.

Le canal collecteur intracytoplasmique, sur l'ultrastructure duquel nous reviendrons ultérieurement, est nettement plus apparent chez Anthophora, il émet un grand nombre d'expansions qui se mettent en rapport avec les vacuoles sécrétoires.

Les inclusions cytoplasmiques diffèrent par certains points de celles que l'on rencontre chez Eucera. L'appareil de Golgi est plus typique. Le chondriome, très développé, est constitué par des mitochondries allongées, aux cristae épaissies. Fait intéressant, nous pensons observer chez certains individus des formes de transition (pl. IX, fig. 1) entre les mitochondries et les vacuoles sécrétoires. On observe en effet par place des éléments d'apparence mitochondriale dont une 
extrémité se renfle et dont les cristae se disjoignent, la matrice mitochondriale parait renfermer un matériel de consistance finement granulaire. Dans d'autres enclaves, les cloisons internes paraissent repoussées vers les parois et sont encore plus épaissies. Finalement, on remarque des formations aux contours sphériques, dont les parois, denses aux électrons mais d'épaisseur inégale, renferment une substance d'aspect granulaire.

Chez d'autres individus, dont les cellules glandulaires montrent un noyau fortement plissé, ces structures sont absentes mais elles sont remplacées par de grandes vacuoles. Celles-ci renferment une masse centrale sphérique, de densité comparable au matériel des enclaves du type précédent, mais séparées des minces parois de la vacuole par un anneau de substance moins dense et finement réticulée (pl. IX, fig. 2).
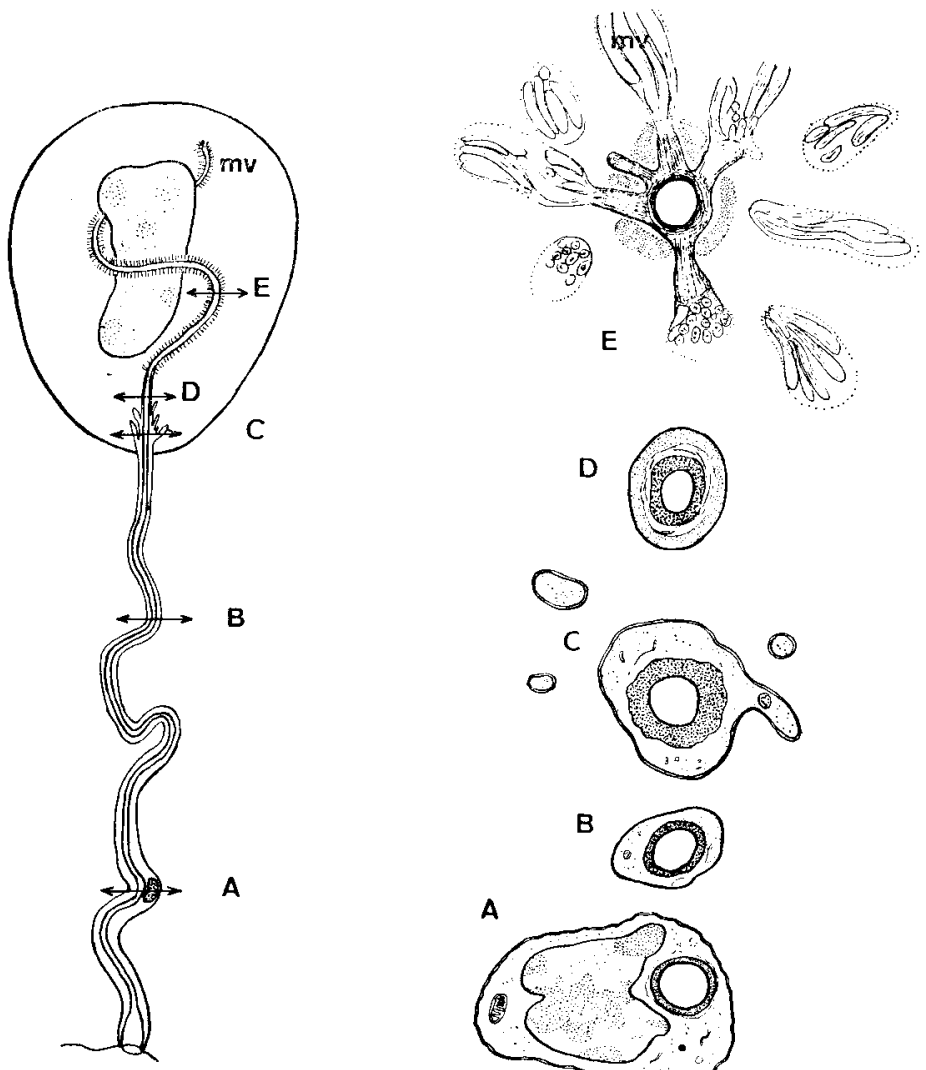

$\mathrm{B}$
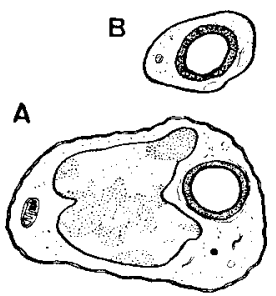

Fic. 2. - Schéma représentant l'ultrastructure du canal excréteur au niveau de coupes transversales pratiquées chez Anthophora en des points du canal situés sur la partie intra et extracellulaire de son trajet. Cette dernière, normalement d'aspect très contourné et enroulée en pelote sur elle-même, est figurée ici de façon rectiligne pour la clarté du schéma. Remarquer les « microvilli» (mv) disposés sur la partie collectrice (E) du canal intracellulaire. Autres explications dans le texte.

ABB. 2. - Schematische Darstellung des Feinbaues des Ableitungskanals in Höhe von Querschnitten, die bei Anthophora am intra-und extrazellulären Teil des Kanals ausgeführt wurden. Der extrazelluläre Abschnitt des Kanals, der normalerweise scharf konturiert und zu einem Knäuel aufgerollt erscheint, ist hier der Ubersichtlichkeit wegen geradlinig gezeichnet. Man beachte die « Mikrovilli » (mv) im Sammelabschnitt (E) des intrazellulären Kanals (Weitere Erläuterungen im Text). 
Par ailleurs, l'ergastoplasme ne prend jamais chez Anthophora les dispositions spiraliformes que nous avons observées chez Eucera. On remarque cependant dans certaines cellules une disposition parallèle des cisternae, qui peuvent se rassembler par groupe de 6 à 10 éléments.

\section{v. - ULTRastructure du CANAL COLIECTEUR}

Chez Eucera, le canal intracytoplasmique, dont le rôle consiste à collecter les produits de la sécrétion glandulaire, ne décrit pas à l'intérieur des cellules sécrétrices un trajet spiral aussi important que chez Bombus ou Anthophora, espèces où il s'enroule en hélice autour du noyau. Toutefois, l'ultrastructure générale du canal collecteur est tout à fait comparable quelle que soit l'espèce considérée. Les figures 2 et 3 résument les variations observées dans la structure fine de ce canal sur des coupes pratiquées transversalement à divers niveaux, en des points situés sur la partie intra ou extracellulaire de son trajet. Ces figures ont été réalisées à partir de micrographies électroniques de la glande d'Anthophora, mais l'aspect des sections transversales est identique dans les deux autres genres.

On remarque une modification de la structure du canal collecteur au fur et à mesure qu'il s'enfonce dans la cellule glandulaire. Les coupes pratiquées en $A$, dans la partie basale de celui-ci, passent au niveau du noyau de la cellule très modifiée qui constitue ce canal collecteur, on observe aussi, dans le mince cytoplasme qui entoure ce noyau une coupe transversale du canal proprement dit. Ce canal comporte à ce niveau une paroi interne épaisse et très dense aux électrons, et de nature cuticulaire.

Au niveau $\mathrm{C}$, les coupes montrent la structure de la cellule collectrice peu après sa pénétration dans le cytoplasme glandulaire. On observe à ce niveau la présence du canal collecteur, entouré d'un reliquat cytoplasmique assez important et diverses sections, de plus faible diamètre, disposées aux alentours du canal. La cellule collectrice émet en effet de nombreuses expansions digitiformes dans la zone où elle pénètre à l'intérieur du cytoplasme glandulaire dont les sections transversales apparaissent autour du canal en C. Les parois du canal comportent à ce niveau 3 couches concentriques bien distinctes. La plus interne est constituée par un matériel homogène, très dense aux électrons. La couche intermédiaire, de faible densité, renferme des inclusions cytoplasmiques diverses et des microtubules; l'externe, plus dense, est de nature granulaire.

Le canal collecteur s'amincit à nouveau au niveau $\mathrm{D}$, il présente alors une couche intermédiaire d'apparence fibreuse, tandis que la couche externe est assez opaque aux électrons.

Mais c'est dans la région où se produit le drainage du matériel sécrété que ce canal présente les différenciations les plus complexes. On assiste dans cette zone $(\mathbf{E})$ à une modification profonde de la couche interne. Celle-ci se diverticulise en une multitude d'expansions latérales digitiformes disposés de façon radiaire et sur une longueur du canal variable selon les espèces - (importante chez Bombus et Anthophora, plus faible chez Eucera (fig. 3). Ces expansions paraissent constituées par un faisceau extrêmement dense de microcanalicules disposés parallèlement. En section transversale, ce faisceau extrêmement dense revêt l'aspect d'un tamis à mailles serrées. A l'extrémité de ces canalicules et en continuité avec ces derniers, 


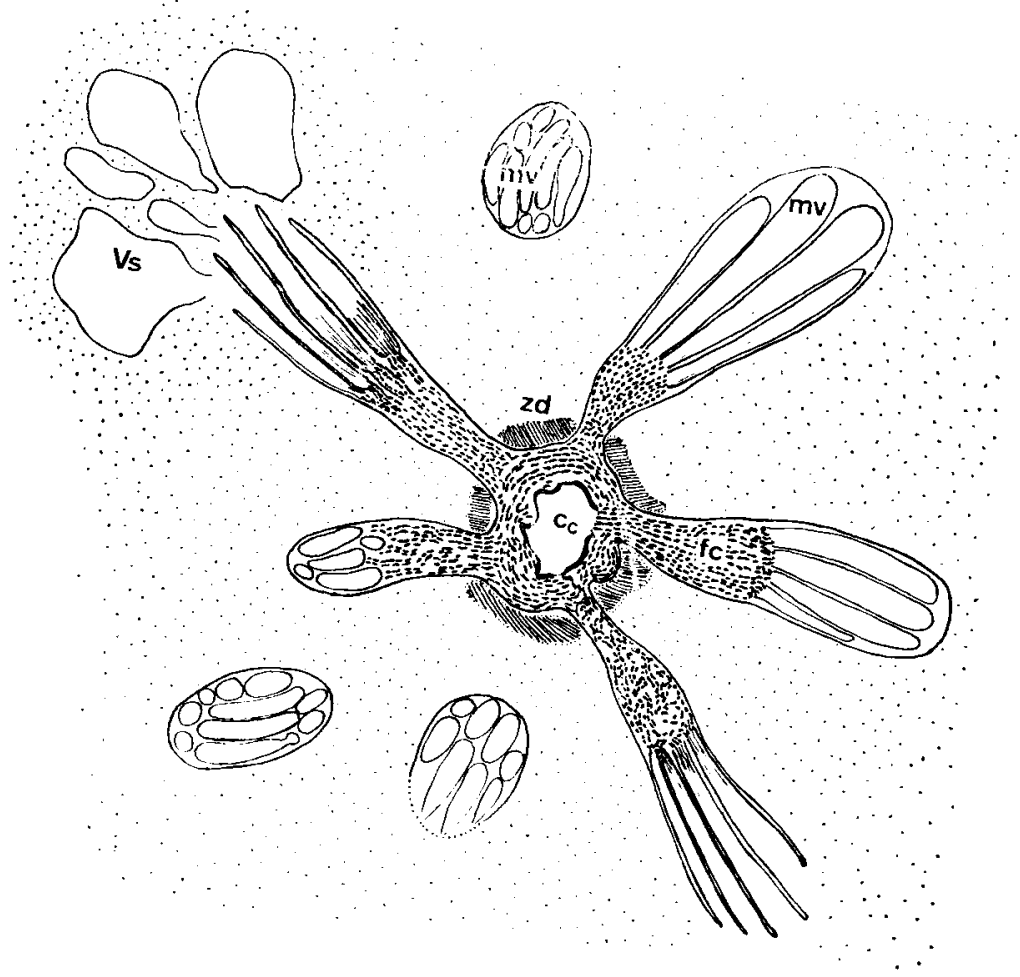

Fic. 3. - Détail de l'ultrastructure de la région à microvilli, reconstituée d'après plusieurs micrographies êlectroniques du canal collecteur (c, canal collecteur: fc, faisceau canaliculaire; mv, microvilli; zd, zone basale dense).

Aв8. 3. - Einzelheit des Feinbaues der Mikrovilli-Zone, nach mehreren elehtronenmikroskopischen Aufnahmen des Sammelkanals zusammengestellt (c = Sammelkanal, fe $=$ Kanalbündel; $\mathrm{mv}=$ Mikrovilli; $\mathrm{zd}=$ dichte Basalzone).

on remarque de nombreuses formations tubulaires, de structure comparable à celle de microvillosités dénommées par STEIN (1962) " microvilli ", chez Bombus. Sur certaines micrographies que nous avons obtenues, ces microtubules semblent se prolonger dans les microvillosités. Celles-ci s'épanouissent dans leur région apicale à proximité des vacuoles sécrétoires, mais il nous est difficile de dire si ces microvilli correspondent à une différenciation du cytoplasme glandulaire, qui se mettrait ainsi en rapport avec les canalicules collecteurs ou si, au contraire, il s'agit d'une modification de la cellule collectrice. Enfin, la paroi externe du canal persiste entre les expansions canaliculaires où elle constitue un matériel granulaire dense aux électrons (pl. VIII, fig. 2).

\section{VI. - Discussion des PRINCIPAUX RéSUltats ET CONCLUSION}

Les deux anthophoridae que nous avons étudiés présentent une certaine similitude anatomique de leurs glandes mandibulaires malgré quelques différences 
morphologiques. Celles-ci concernent la position relative des réservoirs, des canaux excréteurs et de la partie sécrétrice de la glande.

D'autre part, l'histologie classique a permis de montrer que les canalicules intracellulaires déjà remarqués par Nedel, Altenkirch et Landim présentent une nette différence entre Eucera et Anthophora.

Chez Anthophora, où ils sont enroulés en spirale autour des noyaux et passent à proximité de ces derniers, les canaux sécréteurs débouchent dans une formation en peloton (pl. III, fig. 1, ce). Au centre de celle-ci, un espace circulaire bien délimité communiquerait avec le réservoir par un petit canal excréteur. Le réservoir serait en relation directe avec l'extérieur.

Chez Eucera, les canalicules intracytoplasmiques décrivent un arc de cercle autour du noyau et formeraient à l'extérieur de l'ensemble cellulaire un faisceau central collecté par un long canal excréteur très individualisé par rapport au réservoir.

Les diverses techniques histologiques auxquelles nous avons eu recours ont permis de montrer que l'ADN nucléaire est peu concentré, qu'il existe une zone juxtanucléaire très riche en $\mathrm{ARN}$, et qu'une zone cytoplasmique fortement basophile s'observe autour du noyau.

De façon générale, les cellules glandulaires d'Eucera renferment un noyau de forme plus irrégulière (aspect "en croissant)) que celles d'Anthophora. Chez cette dernière espèce, le rapport nucléoplasmique semble plus élevé et la membrane nucléaire présente de nombreux replis.

Chez Eucera il est possible de classer les cellules glandulaires que nous avons étudiées en 2 catégories morphologiques distinctes selon leur aspect ultrastructural, tout en précisant qu'il existe tous les stades intermédiaires entre l'un et l'autre type.

$1^{0}$ Certaines cellules (pl. IV fig. 2) sont caractérisées par un noyau à surface lisse, aux contours réguliers et ovoïdes. Leur cytoplasme renferme un reticulum endoplasmique important mais constitué par des cisternae isolées ou groupées en feuillets parallèles, dispersées régulièrement. On observe aussi de grandes enclaves vacuolaires, à contenu homogène et granuleux, qui représentent à notre avis la forme figurée de la sécrétion, et quelques structures de nature lysosomiale.

$2^{\circ}$ D'autres glandes (pl. IV, fig. 1) renferment des cellules au noyau multilobé, dont la surface est couverte de profonds replis et d'expansions digitiformes. Leur ergastoplasme constitue ici des formations en feuillets parallèles ou en spires concentriques comptant jusqu'à une dizaine de cisternae superposées. On rencontre dans ces cellules une proportion plus importante de mitochondries de grande taille que dans le type précédent, mais elles sont surtout remarquables par l'abondance de corps lamellaires, denses et membranaires qui présentent une similitude certaine avec diverses formations lysosomiales décrites dans de nombreux organes d'insectes par certains auteurs.

On pourrait se demander tout d'abord quelle est la signification fonctionnelle des divers aspects ultrastructuraux que présentent les cellules glandulaires et plus particulièrement quels rapports existent entre les variations observées dans la forme et le développement de l'ergastoplasme et les stades successifs de l'activité sécrétoire? Il nous semble important de souligner qu'à l'intérieur d'une même glande, les cellules sécrétrices possè dent toutes une morphologie identique 
se rapportant à l'un ou l'autre des stades précédemment énumérés ou à une phase d'aspect intermédiaire, ce qui suggère que les éléments sécréteurs présentent un état physiologique identique à un instant donné dans chaque glande.

La corrélation entre les aspects ultrastructuraux d'une cellule glandulaire et les diverses étapes d'un cycle sécrétoire est un problème général de biologie cellulaire et peu de données précises se rapportent aux insectes. La plupart des recherches qui ont eu pour but d'établir le rôle des diverses ultra-structures cytoplasmiques dans l'élaboration de sécrétions chez les insectes, concernent essentiellement des glandes endocrines et surtout les corpora allata (ScHARRER, 1962; FuKada et al., 1966; King et al., 1966; Joly et al., 1968, etc.). La glande prothoracique a aussi donné lieu à des investigations approfondies (BEAUlaton, 1964 et suivantes). Dans le domaine des sécrétions exocrines, le seul travail d'une grande précision expérimentale concernant ce problème est celui de STAÜBLI et al. (1966) qui ont étudié les rapports entre les variations ultrastructurales et l'ergastoplasme dans les cellules épithéliales de moustiques du genre Aedes et le rejet par ces dernières de sécrétions enzymatiques dans la lumière intestinale après un repas de sang.

Ces auteurs distinguent deux étapes dans l'élaboration des enzymes protéolytiques.

$1^{0}$ Une synthèse progressive de ces derniers au niveau des ribosomes, puis leur accumulation dans les cisternae spiralées du réticulum endoplasmique.

$2^{\circ}$ Une désagrégation des spires au moment de la digestion qui faciliterait la libération du matériel protéolytique ainsi accumulé.

Cependant, STAÜBLI et ses collaborateurs envisagent une autre hypothèse dans laquelle les spires représenteraient des structures capables de réagir rapidement à l'ingestion d'un repas par un taux élevé de synthèse protéique, compensant ainsi l'absence de granules préformés que l'on peut observer dans l'intestin d'autres espèces de moustiques.

Les études relatives au rôle des principales ultrastructures cellulaires dans l'élaboration de l'hormone des corpora allata ont conduit les divers auditeurs qui ont abordé ce problème à des conclusions opposées sinon contradictoires. Ainsi, B. Scharrer (1962), voit dans les importantes spires ergastoplasmiques des cellules des corps allates de Leucophaea une phase d'intense activité de synthèse au contraire, JoLy et ses collaborateurs, dans une publication récente (1968) considèrent que les amas spiralés ou concentriques du reticulum endoplasmique se rapportent à des stades de repos de la glande.

Dans les cellules glandulaires d'Eucera, il existe une corrélation très nette entre d'une part : la présence de spires ergastoplasmiques et l'abondance de structures lysosomiales, d'autre part entre l'existence de cisternae ergastoplasmiques dispersées dans le cytoplasme et de grandes vacuoles granulaires de nature sécrétoire.

Il est donc vraisemblable que les glandes mandibulaires dont les cellules présentent un noyau régulier et à cisternae ergastoplasmiques dispersées représentent un stade d'activité du cycle sécrétoire, alors que celles à noyau multilobé et au cytoplasme riche en spires ergastoplasmiques et en structures lysosomiales caractérisent la phase du même cycle, c'est-à-dire un stade de repos ou même d'invo- 
lution qui succéderait à l'émission du produit de la sécrétion dans le canal collec: teur.

Il convient toutefois d'insister sur le caractère hypothétique de ces considérations, en l'absence de données précises sur l'âge réel, l'état physiologique et la phase d'activité nidificatrice des insectes que nous avons prélevés dans la nature pour accomplir cette étude en microscopie électronique.

D'autres recherches s'imposeraient donc pour suivre les variations ultrastructurales de la glande chez des animaux élevés en laboratoire et auxquels on prélèverait ces dernières à des intervalles de temps précis après leur sortie de la loge de nymphose et pendant les diverses phases de la nidification.

\section{Reçu pour publication en février 1970. Eingegangen im Februar 1970.}

\section{ZUSAMMENFASSUNG}

Es wird über die Untersuchungsergebnisse verschiedener histologischer und Feinbau-Untersuchungen an den Mandibeldrüsen von Eucera longicornis Scop. und Anthophora acervorum Lat. berichtet.

Histologisch weisen die Drüsenzellen von Eucera bei einzelnen Individuen grosse Unterschiede auf. Ihre Kerne sind polymorphe, unregelmässige Gebilde, deren Oberfläche stellenweise tief eingestülpt ist. Häufig sind sie " halbmondförmig ».

Bei Anthophora sind die Kerne im allgemeinen von regeimässigerer Gestalt; ihre Oberfläche ist viellappig. Obgleich sie ebenfalls polymorph sind, tritt die bei der vorigen Art beobachtete "Haibmondform " bei ihnen seitener auf.

Der Desoxyribonucleinsäure-Gehalt der Kerne ist nicht sehr hoch; die Feulgen-Reaktion ist sowohl bei Anthophora als auch bei Eucera nur schwach positiv. Dagegen zeigt die Unnafärbung kombiniert mit Methylpyronin-Grün beim Ribonukleasetest eine starke Basophilie in der Perinuklearzone des Cytoplasmas. Die Basophilie resultiert aus einer Ribonuclein-Konzentration in dieser Region.

Bei Eucera tritt die Basophilie besonders stark in der konkaven Einbuchtung der halbmondförmigen Kerne auf. In dieser kernnahen Zone befindet sich eine homogene, stark pyroninophile Masse. Mit Hilfe des Elektronenmikroskops konnte festgestellt werden, dass es sich hierbei um ein ausserhalb des Kerns durch Anhäufung einer grossen Zahl von Palade-Grana und Ergastoplasma Zisternen entstandenes Gebilde handelt.

Ferner stellten wir wichtige Unterschiede im Feinbau der Drüsenzellen von Eucera in Abhängigkeit vom Fangdatum der Tiere fest. Auf Grund ihres Feinbaues lassen sich zwei extreme Typen von Drüsenzellen unterscheiden. Die einen, die einen regelmässigen Kern aufweisen, besitzen ein im gesamten Cytoplasma verteiltes Ergastoplasma und schliessen zahlreiche Sekret vakuolen ein (Tafel IV, Abb. 2). Bei den anderen dagegen ist der Kern sehr unregelmässig, oft zwei- oder mehrlappig und tief eingebuchtet (Tafel IV, Abb. 1 u. Tafel V). Diese Form entspricht vermutlich der im Lichtmikroskop beobachteten " Halbmondform ". Hier ist das Ergastoplasma entweder spiralig aufgerollt oder aus konzentrisch gestapelten Zisternen gebildet. Dieser Zelltyp enthält sehr viele polymorphe Vakuolen-Einschlüsse, was auf lysosomiale Strukturen zurückgeführt wird (Tafel VII, Abb. 1 u. 2). Zwischen diesen beiden Typen des Feinbaues kommen alle Arten von Zwischenstadien vor.

Bei Anthophora konnte im Feinbau des Kerns eine derartig ausgeprägte Variabilität nicht festgestellt werden. Mitochondrien sind zahlreicher vorhanden als bei Eucera und weisen, entsprechend der Tätigkeit der Sekretvakuolen, bedeutende Unterschiede im Feinbau auf (Tafel IX, Abb. 1). 
Im Mikroskop weist die Anatomie der Ableitungskanäle beider Arten grosse Unterschiede auf. Bei Anthophora sind die Kanäle spiralig um den Kern gewunden und erstrecken sich in das Cytoplasma der Drüsenzelle. Der extrazelluläre Teil des Kanals ist zu einem Knäuel zusammengerollt (Tafel III, Abb. 1). Bei Eucera ist der im Cytoplasma befindliche Teil des Kanals kurz und legt sich nicht um den Kern sondern bleibt auf die Peripherie des Cytoplasmas beschränkt, wobei der extrazelluläre Teil fast gerade und deutlich länger als bei Anthophora ist (Tafel I, Abb. 1).

Der Feinbau der Ableitungskanäle hingegen zeigt in beiden Fälen grosse Ahnlichkeit. Er stimmt vollständig mit dem von STEIN (1962) bei Bombus terrestris beschriebenen überein.

Weitere Untersuchungen des Feinbaues werden nötig sein, um den Sekretionszyklus bei im Labor gezogenen Insekten bekannten Alters und physiologischen Zustandes genau zu bestimmen.

\section{RÉFÉRENCES BIBLIOGRAPHIQUES}

Altenkirch G., 1962. Untersuchungen über die Morphologie der abdominalen Hautdrüsen einheimischer Apiden (Insecta, Hymenoptera). Zool. Beitr, Berlin (N.S.), 7, 161-238.

Beaulaton J., 1967. Localisation d'activités lytiques dans la glande prothoracique d'Antheraea pernyi Guer au stade prénymphal. I. Structures lysosomiques, appareil de golgi et ergastoplasme. J. Micr., 6, 179-200.

- 1967, b. Localisation d'activités lytiques dans la glande prothoracique d'Antheraea pernyi Guer au stade prénymphal. II. Les vacuoles autolytiques (cytolysomes). J. Micr., 6, 349-370.

- 1968. Étude ultrastructurale et cytochimique das glandes prothoraciques du ver à soie au $4^{\mathrm{e}}$ et $5^{\mathrm{e}}$ stades larvaires. J. Ultrastruct. Res., $23, \mathrm{n}^{\mathrm{o}}$ 5-6, 474-536.

Bordas L., 1894. Appareil glandulaire des Hyménoptères (gl. salivaires, tube digestif, tubes de Malpighi et gl, venimeuses). Thèse. Paris, G. Masson, 362, p $11 \mathrm{pl}$.

Farquhar M. G., Palade G. E., 1965. Cell junctions in amphibian skin. J. Cell. Biol., 26, 263.

Fukuda S., Eguchi G., Takeuchi S., 1966. Histological and electron microscopical studies on sexual difference in structure of the corpora allata of the moth of the silkworm B. mori. Embryologia, 9, (2), 123-158.

Héroin Y., 1966. Étude des constructions d'Osmia carnuta (Hym. Apoidea) après injections de produits marqués. C. R. Soc. Biol., 160, no 11, 2027-2030.

Heselhaus F., 1922. Die Hautdrüsen der Apiden und verwandter Formen. Zool. Jb. Abt. Anat. u. Ontog., 43, 369-464.

Joly L., Joly P., Porte A. et Girardie A., 1968. Étude physiologique et ultrastructurale des corpora allata de Locusta migratoria L. (Orthoptère) en phase grégaire. Arch. Zool. Exp. Gen., $109,4,703-728$.

Kelly D. E., 1966. Fine structure of Desmosomes, Hemidesmosomes and an adepidermal globular layer in developing new epidermis. J. Cell. Biol., 28, 51-72.

King R. C., Aggarmal S. K. et Bodenstein D., 1966. The comparative submicroscopic cytology of the corpus allatum, corpus cardiacum complex of wild type and fes adult of Drosophila melanogaster. J. exper. Zool., 161, (2), 151-75.

Kans J. Entomol. Soc., 38, (3), 209-233.

Kratky E., 1931. Morphologie und Physiologie der Drüsen in Kopf und Thorax der Honigbiene. Z. wiss. Zool., 139, 120-200.

Landrm C. da Cruz, 1968. Histoquimica e ultrastructura das glandulas salivares das Abelhas (Hym. Apoidea). Arq. Zool. Sao Paulo, 17, (3), 133-166.

Low F. N., 1962. Microfibrils : fine filamentous components of the tissue space. Anat. Rec., 152, 131-137.

Mathewson J. A., 1965. The internal morphology of the Eastern cucurbit bee, Peponapis pruinosa (Hym. Apoidea). J. Kansas Entom. Soc. 38 (3) : 209-233.

Nedel J. O., 1960. Morphologie und Physiologie der Mandibeldrüse einiger Bienenarten (Apoidae). Z. Morphol. Okol. Tiere, 49, 139-183. 
Scharrer B., 1964. Histologica! studies on the corpus allatum of Leucophaea maderae. IV. Ultrastructure during normal activity cycle. Z. Zellforsch., $62,125-148$.

Scharrer B., 1966. Ultrastructural study of the regressing prothoracic glands of Blattarian insects. Z. Zellforsch., 69, 1-21.

SchiemenZ P., 1883. Uber das Herkommen des Futtersaftes und die Speicheldrüsen der Biene nebst einem Anhang über das Riechorgan. Z. wiss. Zool., 38, 71-135.

Staubli W., Freyvoged T. A., Suter J., 1966. Structural modification of the endoplasmic reticulum of midgut epithelial cells of mosquitoes in relation to blood intake. J. Micr., 5, 189-204.

Steiv G., 1962. Uber den Feinbau der Mandibeldrüse von Hummelmännchen. Z. Zellforsch., 57, 719-736.

Stein G., 1966 a. Uber den Feinbau der Duftdrüsen von Feuerwanzen (Pyrrhocoris apterus L., Geocorisae). I. Mitt.-Zur Funktionellen Morphologie der Drüsenzelle. Z. Zellforsch., 74, 271-290.

STElN G., 1966 b. Uber den Feinbau der Duftdrüsen von Feuerwanzen (Pyrrhocoris apterus L., Geocorisae). II. Mitt.-Das ableitende Kanalsystem und die nichtdrüsigen Anteile. Z. Zellforsch., $75,501-516$.

Wohlfarth-Botrermann K. E., Moericke V., 1960. Zur funktionellen Morphoologie der Speicheldrüsen von Homopteren. III. Mitt.-Die Nebendrüse von Myzus persicae Sulz. Z. Zellforsch., $52,346-61$.

\section{Abréviations utilisées dans Les planches}

\section{Erläuterung zu den AbKürzungen in den TafelN}

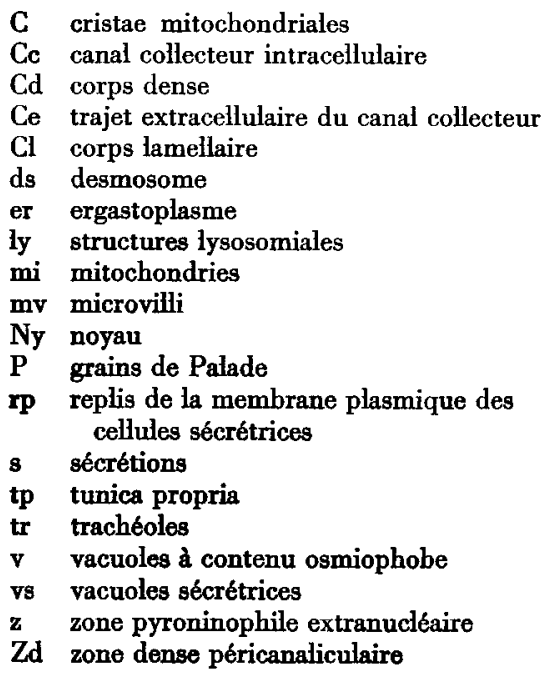

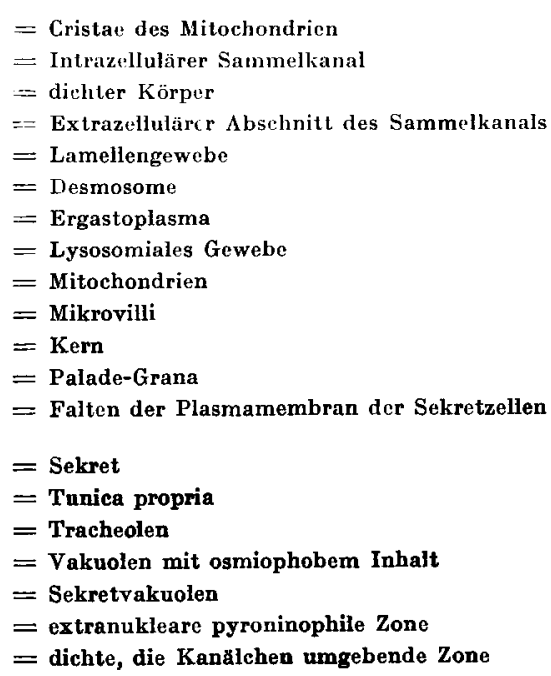




\section{PLANCHE I}

Histologie de la glande mandibulaire d'Eucera

FIg. 1. - Cliché à petit grossissement d'une coupe transversale de la glande mandibulaire colorée à l'hémalun-éosine.

FIG. 2. - Portion du même cliché plus grossie. Remarquer la présence de noyau " en croissant " et, au bas de la photographie, les canalicules excréteurs groupés en faisceau.

Fig. 3. - Cellules glandulaires colorées au bleu de toluidine tamponné au pH 4,6 : la zone périnucléaire est plus basophile que le reste du cytoplasme.

TAFEL I

Histologie der Mandibeldrüse von Eucera

Aвв. 1. - Schwach vergrösserter Querschnitt durch dieMandibeldrüse;Färbung: Hämalaun-Eosin.

AвB. 2. - Einzelheit des gleichen Bildes, stark vergrössert. Man beachte den halbmondförmigen Kern und, unten im Bild, die zu Bündeln angeordneten Ableitungskanälchen.

Aвв. 3. - Drüsenzellen; pH 4,6; Färbung Toluidinblau. Die Perinuklearzone ist basophiler als das übrige Cytoplasma. 
Apidologie, 1970, 1 (3).

P1. I

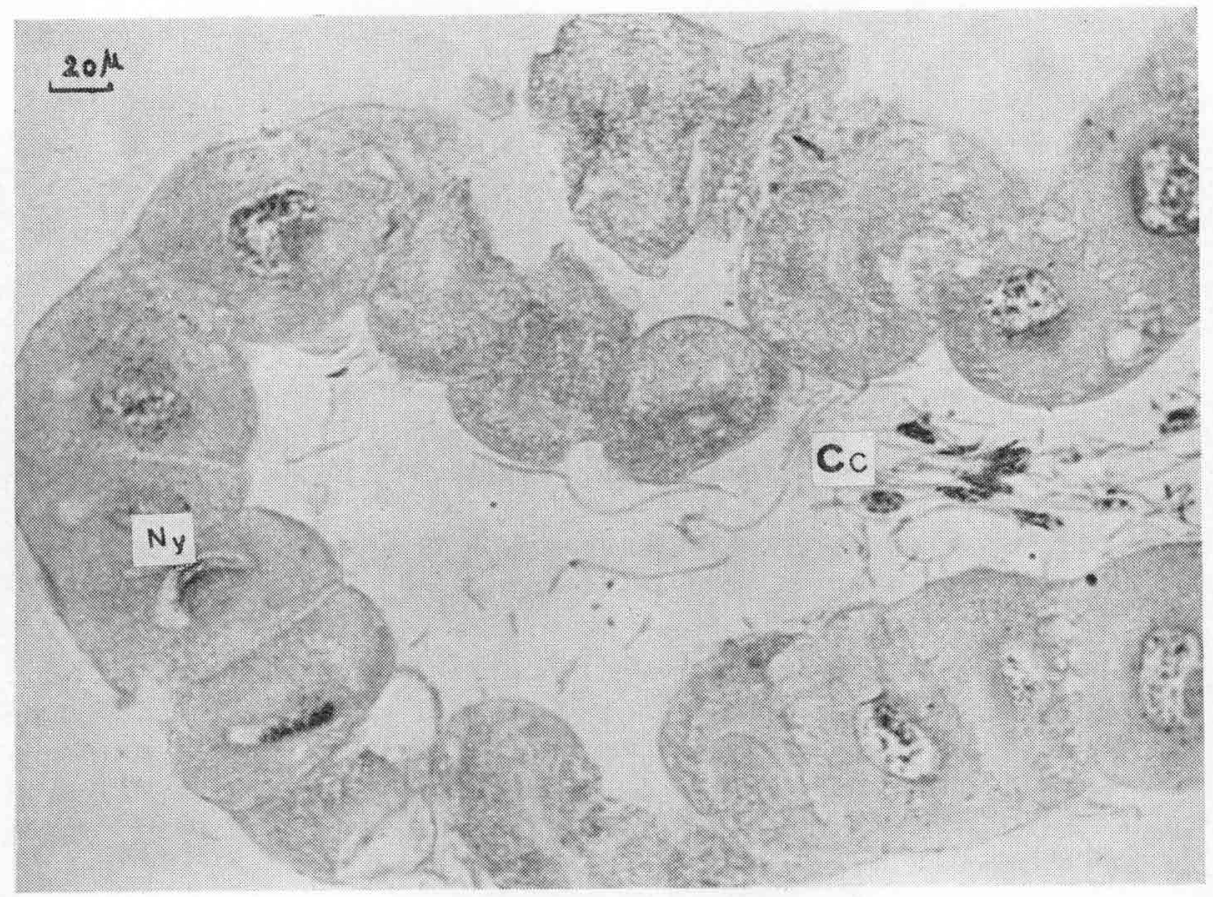

1

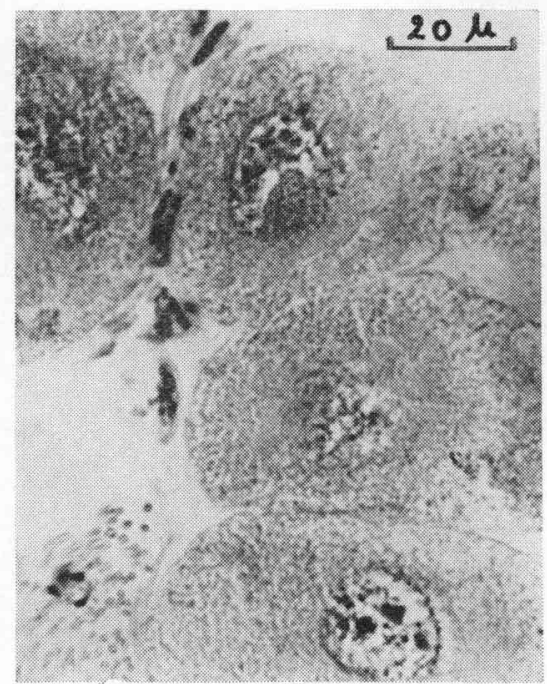

2

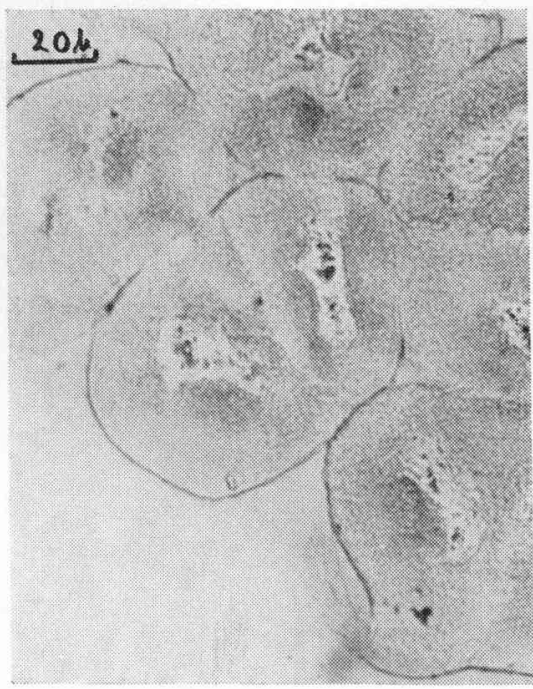

3

Yronne HEROIN, François RAMADE. 


\section{PLANCHE II}

\section{Histologie de la glande mandibulaire d'Eucera}

Fig. 1. - Coupe de glande colorée au Feulgen. Remarquer ici encore la présence de noyau " en croissant " et l'intense colorabilité des noyaux des cellules canaliculaires.

Fig. 2 et 3. - Glande sur laquelle on a pratiqué le test de Unna-Pappenheim. On remarque sur le cliché de gauche l'existence d'une masse très pyroninophile (z) logée dans les dépressions nucléaires. Sur celui de droite, correspondant à une préparation digérée à la RNase, cette masse a disparu alors que les noyaux des cellules glandulaires demeurent fortement colorés au vert de méthyle.

\section{TAFEL II}

\section{Histologie der Mandilbeldrïse von Eucera}

Авв. 1. - Schnitt durch die nach Feulgen gefärbte Drüse. Man beachte auch hier den halbmond-förmigen Kern und die intensive Färbung der Kerne in den Zellen der Kanälchen.

Авв. 2 и. 3. - Drüse nach Unna-Pappenheim-Test. Links im Bild siecht man eine stark pyroninophile Zone $(Z)$ in den Kerneinbuchtungen. Rechts - nach der Ribonuklease - ist diese Zone verschwunden und die Drüsenzellkerne sind stark mit Methylgrün gefärbt. 


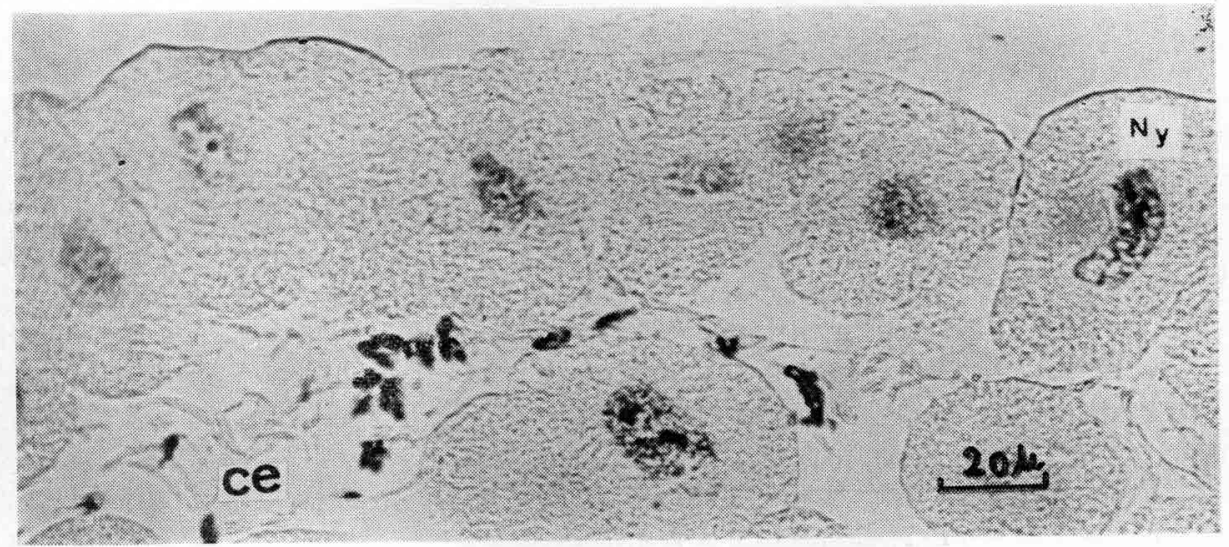

1

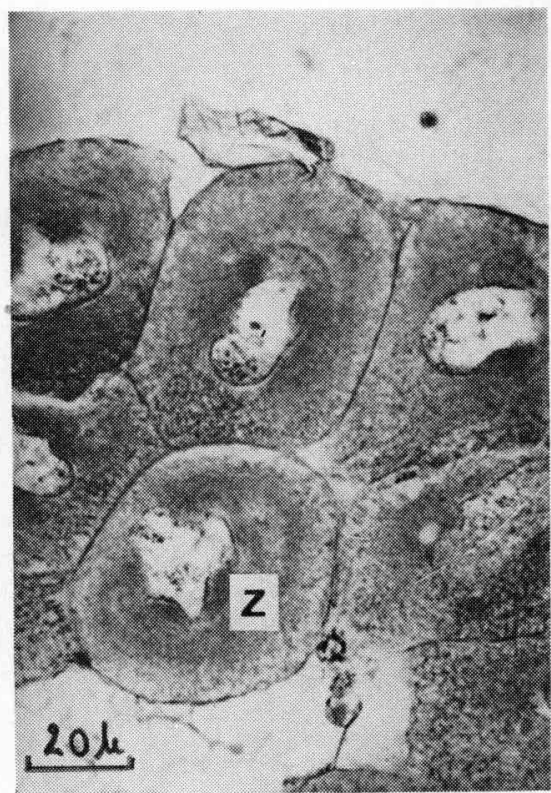

2

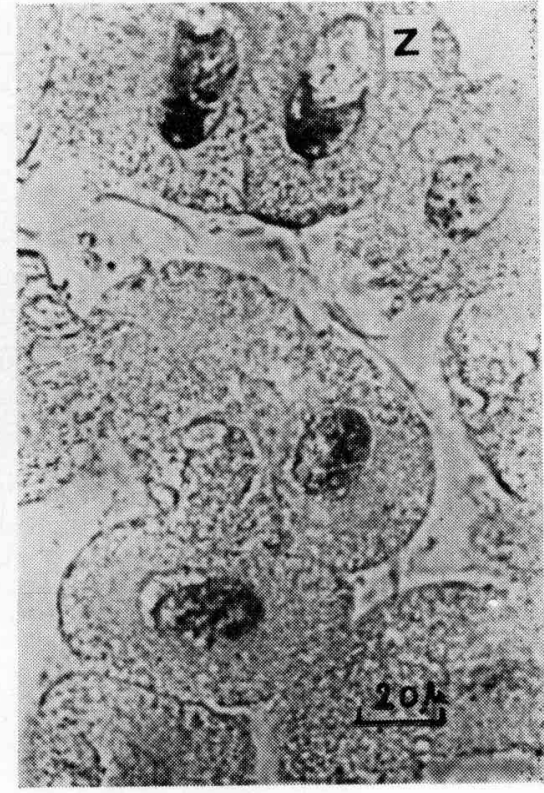

3

Yvonne HEROIN, François RAMADE. 
PLANCHE III

\section{Histologie de la glande mandibulaire d'Anthophora}

FIG. 1. - Cliché à petit grossissement d'une coupe transversale de glande mandibulaire colorée à l'hémalun-éosine. Le réservoir est ici entouré par les cellules sécrétrices et les canalicules excréteurs, très contournés, pelotonnés, se déversent individuellement dans celui-ci.

FIG. 2. - Détail d'une cellule sécrétrice : on observe au centre du cliché le trajet intracellulaire du canalicule excréteur qui comporte la zone microvillienne (en section oblique) et la zone excrétrice.

Fig. 3. - Vue à fort grossissement d'une autre cellule glandulaire. Le trajet intracellulaire d'un canalicule excréteur est bien visible au centre du cliché. On remarque aussi, légèrement au-dessus de la spire qu'il décrit, une section oblique de ce même canal et le halo constitué par la zone microvillienne qui l'entoure.

TAFEL III

\section{Histologie der Mandibeldrüse von Anthophora}

AвB. 1. - Schwach vergrösserter Querschnitt durch eine mit Hämalaun-Eosin gefärbte Mandibeldrüse. Hier ist das Reservoir von Sekretzellen umgeben, und die stark gewundenen zu einem Knäuel gestapelten Ableitungskanälchen erstrecken sich einzeln in das Lumen.

Авв. 2. - Ausschnitt aus einer Sekretzelle. In der Mitte erkennt man den intrazellulären Abschnitt des Ableitungskanälchens mit der Mikrovilli-Zone schräg angeschnitten) sowie die Sekretions zone.

Авв. 3. - Eine endere stark vergrösserte Drüsenzelle. In der Mitte ist der intrazelluläre Abschnitt eines Ableitungskanälchens gut zu erkennen. Ausserdem bemerkt man, wenig oberhalb der von ihm gebildeten Spirale, den schräg angeschnittenen Kanal, der von der Mikorvilli-Zone umschlossen ist. 


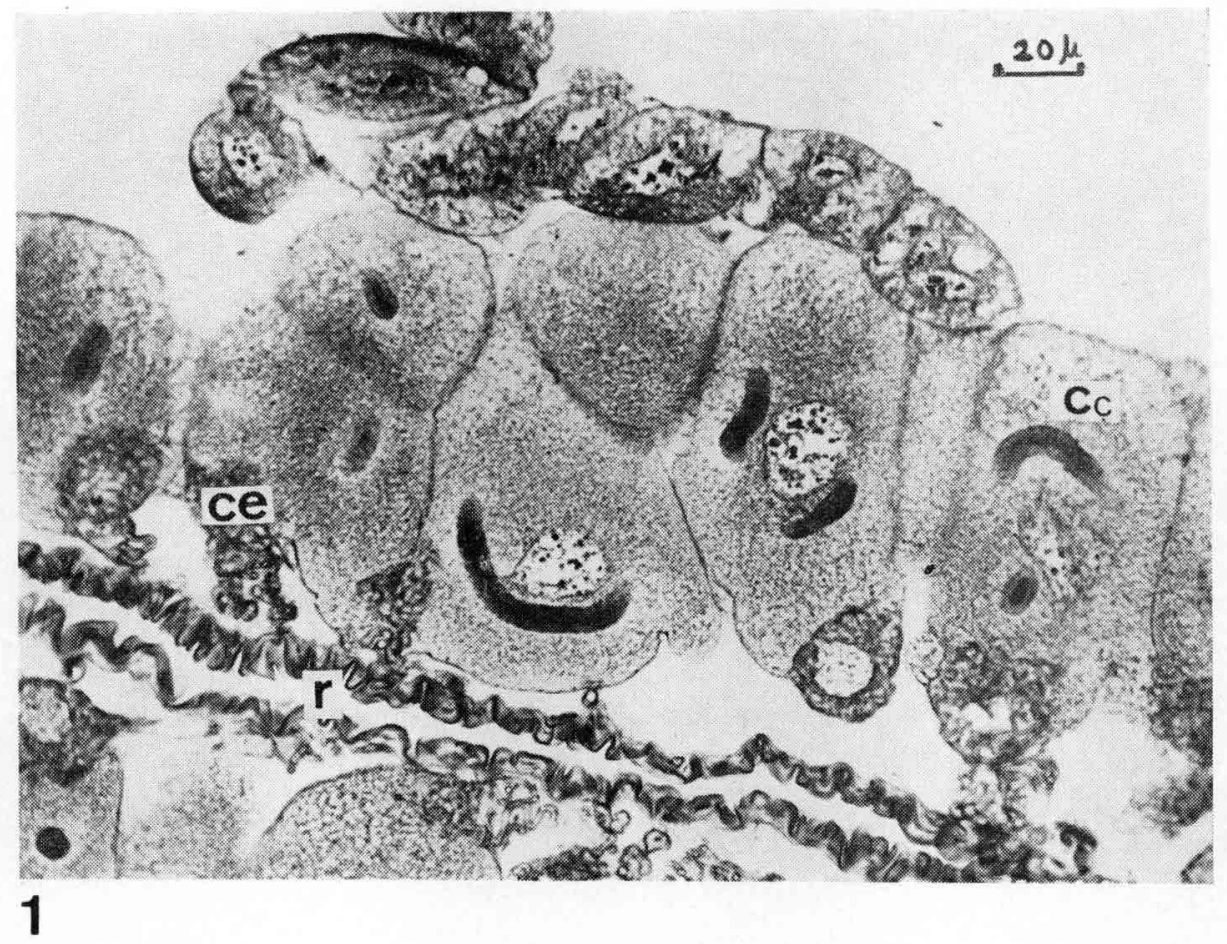

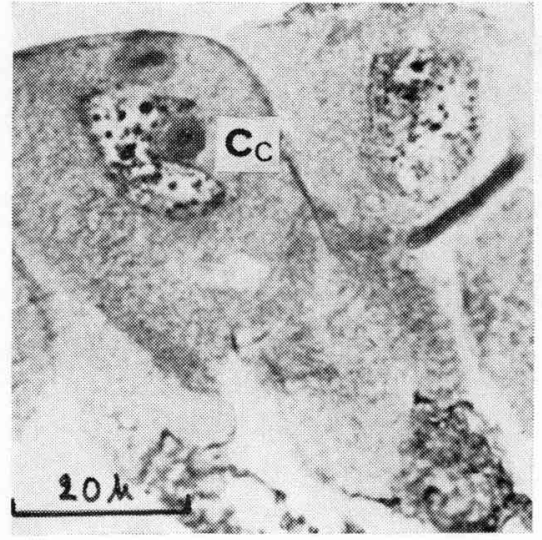

2

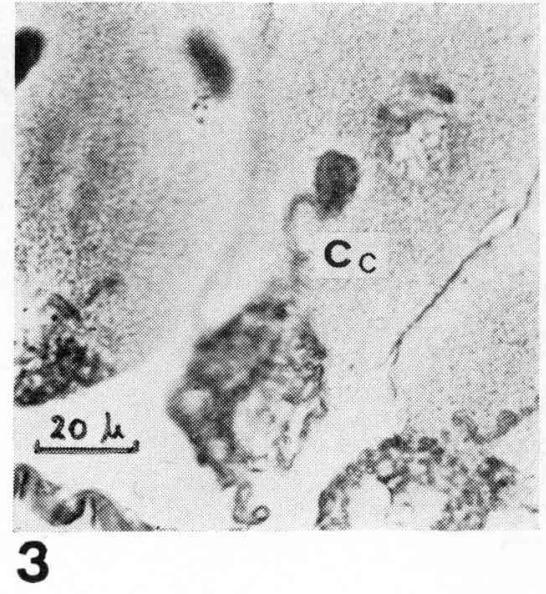

Yvonne HÉROIN, François RAMADE. 


\section{PLANCHE IV}

\section{Ultrastructure de la glande mandibulaire d'Eucera}

Fig. 1. - Cliché d'une cellule sécrétrice à noyau plurilobé. L'ergastoplasme disposé en anneau concentrique se localise préférentiellement dans la partie concave située entre deux lobes nucléaires.

Fic. 2. - Cliché d'une cellule sécrétrice à noyau régulier, subsphérique. Ici, l'ergastoplasme est uniformément réparti dans l'ensemble du cytoplasme dans lequel on observe des cisternae isolées.

(Ces micrographies ainsi que celles des planches suivantes ont été réalisées avec le microscope électronique Hitachi HS 7 du Laboratoire de Zoologie de l'Institut national agronomique. Sauf spécification contraire, les échelles figurées en bas et à droite des clichés figurent une dimension de 2 microns).

TAFEL IV

\section{Feinbau der Mandibeldrüse von Eucera}

Авв. 1. - Sekretzelle mit mehrlappigem Kern. Das ringförmige Ergastoplasma befindet sich vorzugsweise in den konkaven Stellen zwischen zwei Kernlappen.

Aвв. 2. - Zelle mit fast kugeligem Kern. Hier ist das Ergastoplasma gleichmässig im gesamten Cytoplasma verteilt, das einzelne Zisternen aufweist. (Diese Mikrophotographien, ebenso wie die der folgenden Tafeln wurden mit dem Elektronen-Mikroskop Hitachi HS 7 des Zoolog. Laboratoriums des Institut National Agronomique angefertigt. (Abgesehen von anderslautenden Angaben bedeutet der unten rechts auf den Abb. eingezeichnete Masstab $=2$ Mikron). 
Apidologie, 1970, 1 (3).

Pl. IV
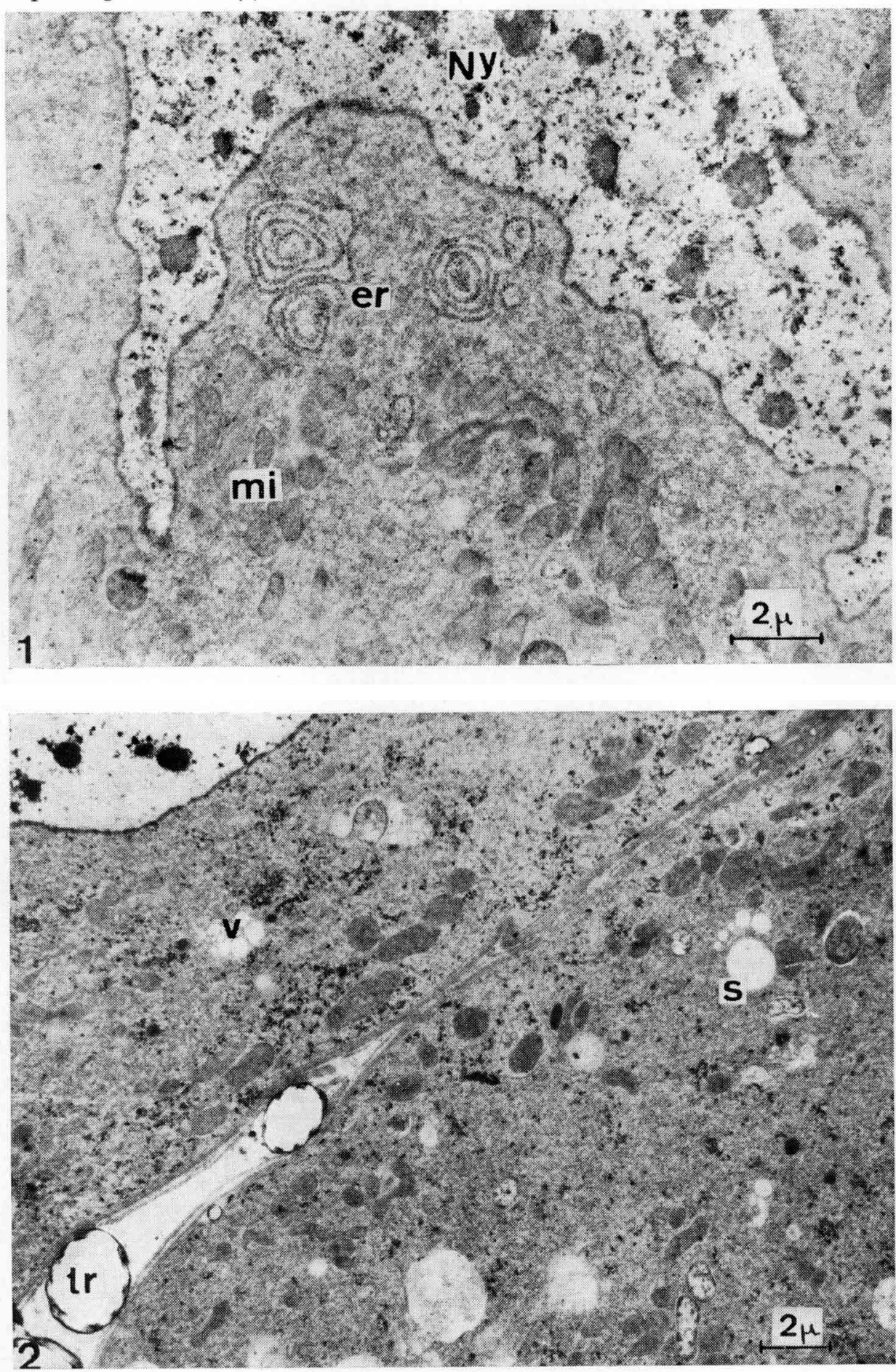

Yvonne HÉROIN, François RAMADE. 


\section{PLANCHE V}

Ultrastructure de la glande mandibulaire d'Eucera

Reconstitution (4 clichés accolés) d'une partie de la région périnucléaire dans une cellule sécrétrice. On observe au bas du cliché la limite de cette dernière avec un élément glandulaire voisin et la présence d'un desmosome à la jonction de deux membranes plasmiques (Ds). Le cytoplasme renferme de nombreuses mitochondries (Mi), des formations lysosomiales (Ly, me) et il existe des amas de grains de Palade $(\mathrm{P})$ dans la zone proxinucléaire.

\section{TAFEL V}

\section{Feinbau der Mandibeldrüse von Eucera}

Darstellung (4-aneinandergefügte Aufnahmen) eines Ausschnittes der Perinuklearzone in einer Sekretzelle. Unten im Bild ist der Rand dieser Zelle mit benachbartem Drüsenelement zu erkennen sowie ein Desmosom an der Verbindungsstelle zweier Plasmamembranen (Ds). Das Cytoplasma umschliesst zahlreiche Mitochondrien (mi), lysosomiale Strukturen (Ly, me) und Anhäufungen von PaladeGrama (P) in der Proxinuklearzone. 
Apidologie, 1970, 1 (3).

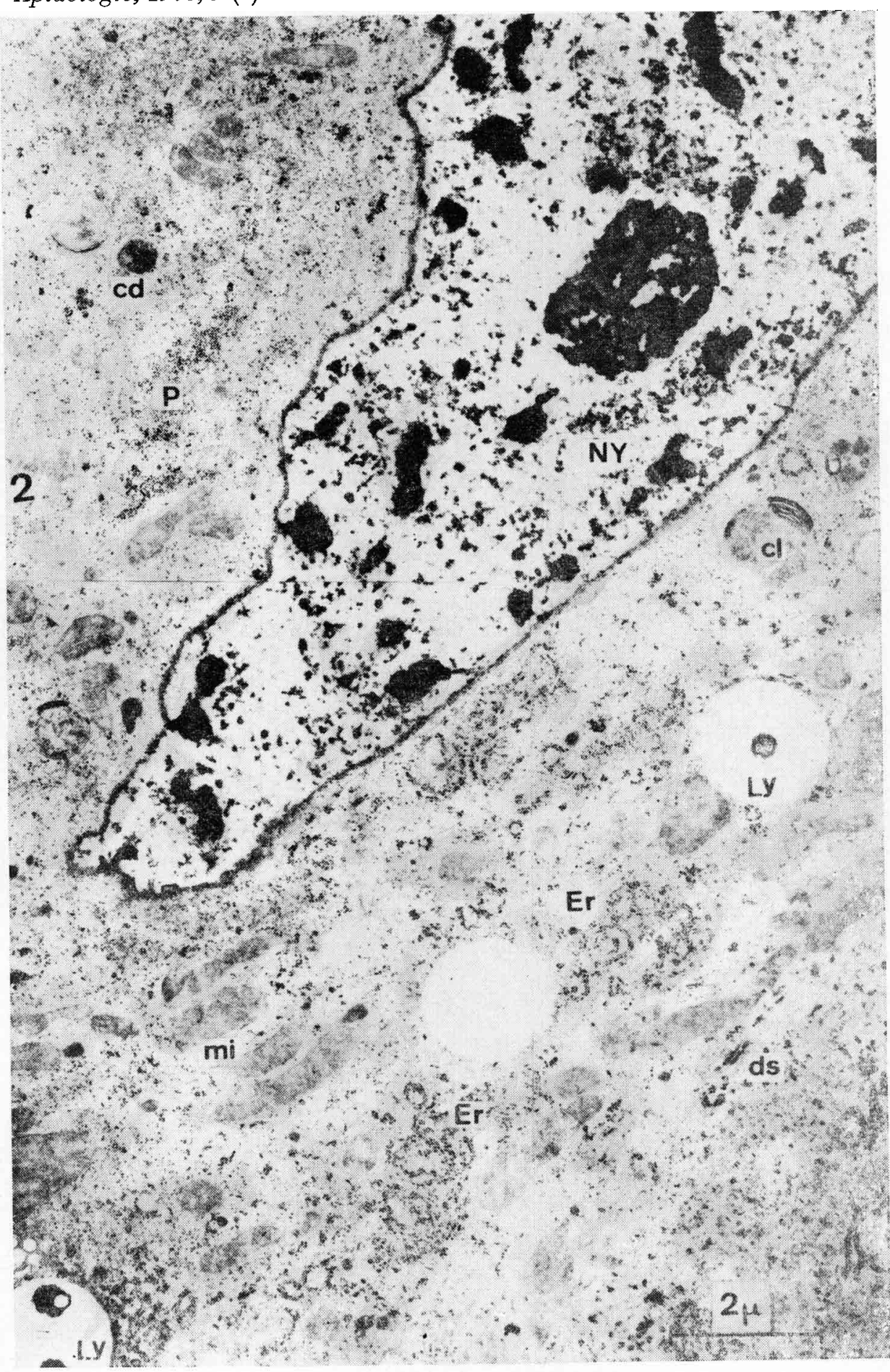

Yvonne HÉROIN, François RAMADE. 


\section{PLANCHE VI}

\section{Ultrastructure de la glande mandibulaire d'Eucera}

FIg. 1. - Vue partielle à petit grandissement d'une cellule glandulaire à noyau plurilobé. On remarque la présence de nombreuses formations ergastoplasmiques spiralisées ou disposées en anneaux concentriques et de multiples structures lysosomiales.

FIG. 2. - Vue à plus fort grandissement d'une partie du cliché précédent. Remarquer la Tunica propria qui enveloppe la cellule glandulaire et les replis de la membrane plasmique.

\section{TAFEL VI}

\section{Feinbau der Mandibeldrüse von Eucera}

Aвв. 1. - Schwach vergrößerte Teilansicht einer Drüsenzelle mit mehrlappigem Kern. Man bemerkt zahlreiche spiralige oder in konzentrischen Ringen angelegte Ergastoplasma-Gebilde und viele 1ysosomiale Strukturen.

AвB. 2. - Stärker vergrösserte Teilansicht der vorherigen Abbildung. Man beachte die Tunica propria, die die Drüsenzelle und die Falten der Plasmamembran umschliesst. 
Apidologie, 1970, 1 (3).

Pl. VI
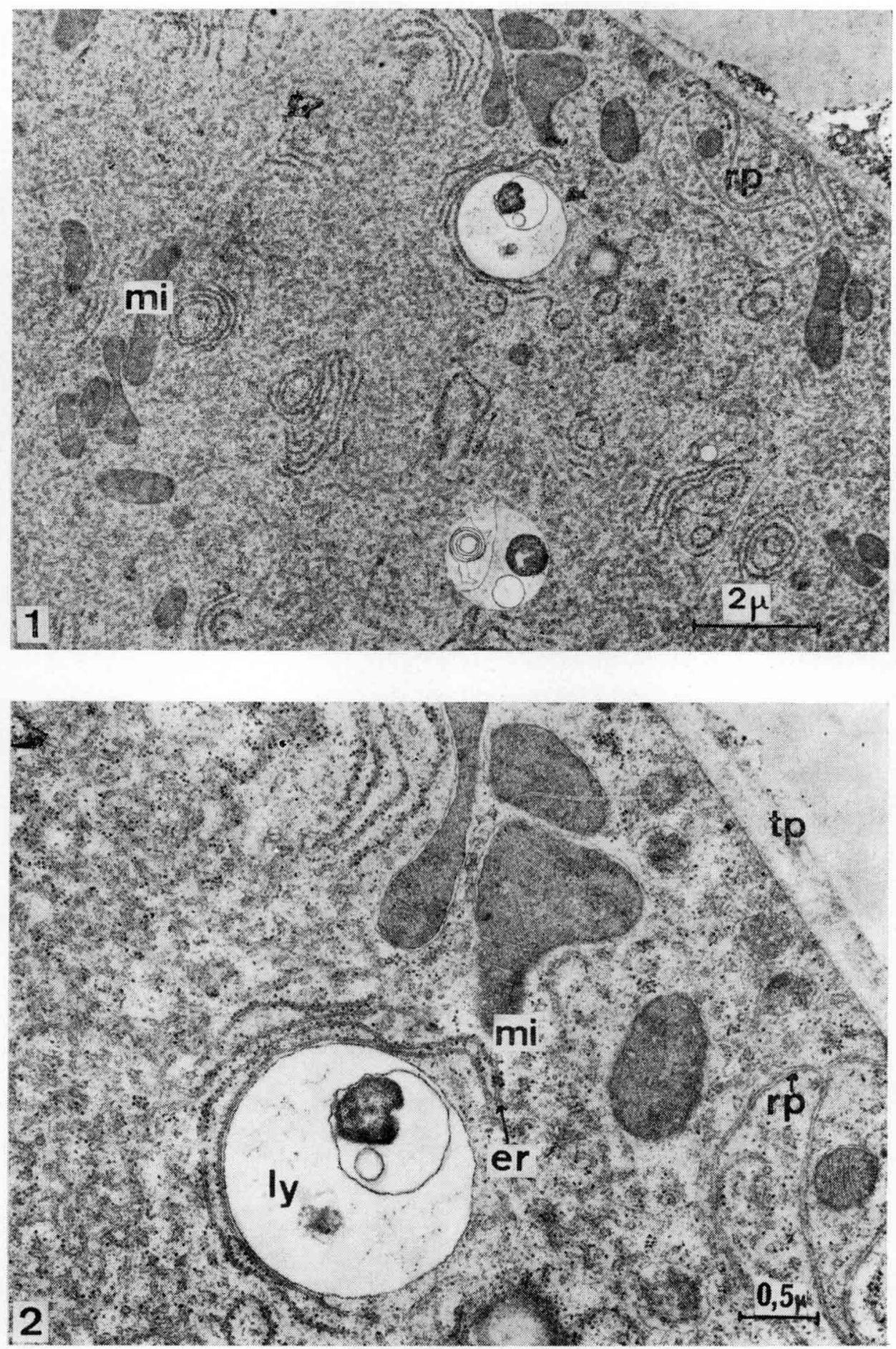

Yvonne HÉROIN, François RAMADE. 


\section{PLANCHE VII}

Ultrastructure de la glande mandibulaire d'Eucera

FIG. 1. - Vue à petit grandissement d'une partie du cytoplasme d'une cellule glandulaire à une phase correspondant à la période d'évacuation du produit secrété : de grandes vacuoles au contenu granulaire sont disposées tout autour du canal excréteur.

Fig. 2. - Détail de mitochondries : remarquer dans le chondriosome situé au bas et à gauche du cliché la présence de cristae de forme elliptique.

TAFEL VII

Feinbau der Mandibeldrüse von Eucera

Aвв. 1. - Schwach vergrösserter Cytoplasma-Ausschnitt einer Drüsenzelle in der Sekretionsphase : grosse, Granula enthaltende Vakuolen liegen rund um den Ableitungskanal.

Aвв. 2. - Ausschnitt mit Mitochondrien. Man beachte die elliptischen Cristae im Chondriosom, unten links im Bild. 

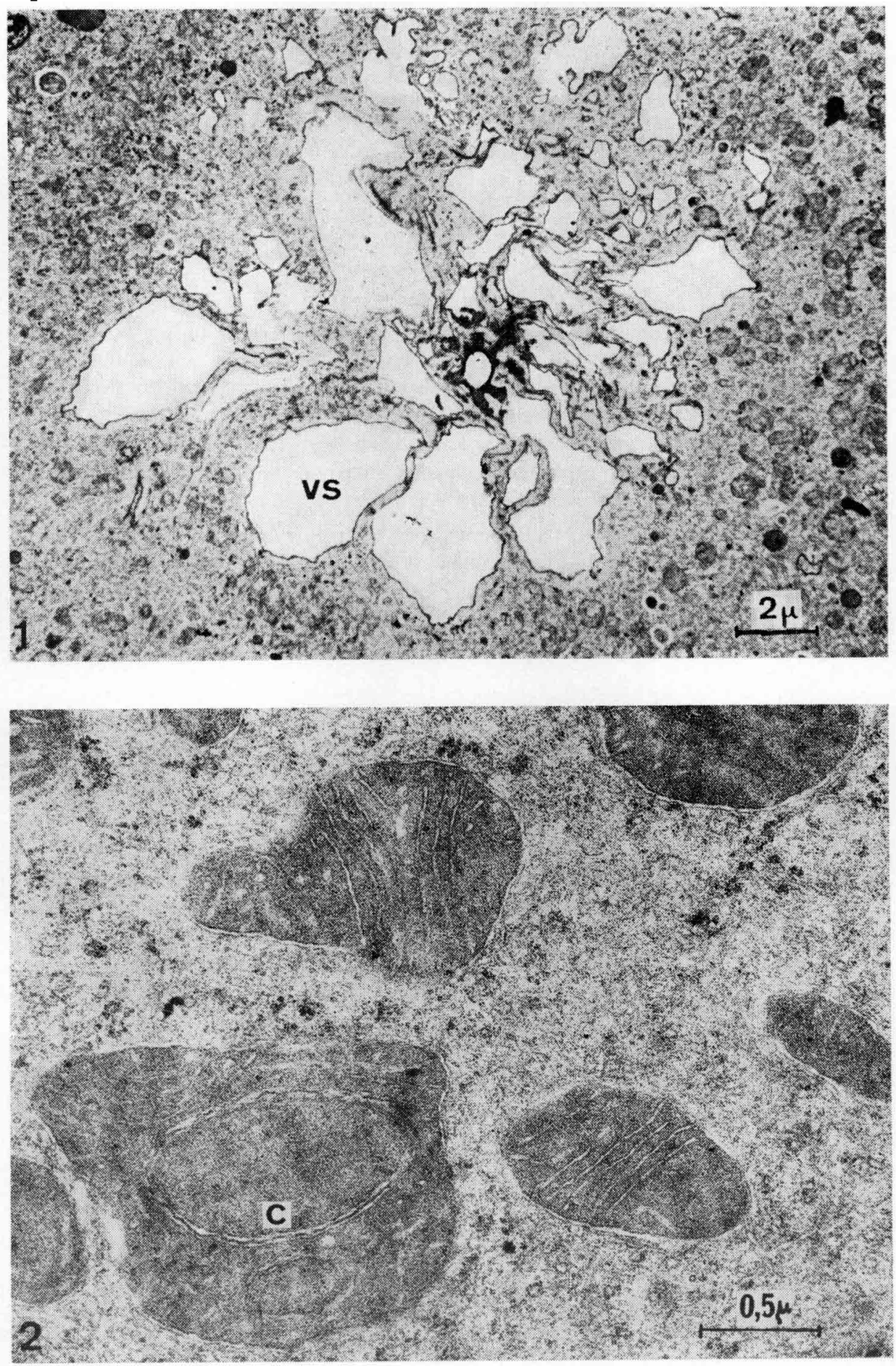

Yvonne HÉROIN, François RAMADE. 


\section{PLANCHE VIII}

\section{Ultrastructure de la glande mandibulaire d'Anthophora}

Fig. 1. - Vue d'ensemble d'une cellule secrétrice. On remarque à droite du noyau le grand développement du canal excréteur intracytoplasmique et les coupes transversales ou obliques des nombreuses expansions digitiformes des parois du canal qui se prolongent par des microvilli dans le cytoplasme de la cellule glandulaire.

FIg. 2. - Cliché à plus fort grandissement du canal intracytoplasmique en coupe transversale. On remarque les expansions digitiformes des parois de ce canal, qui paraissent constituées par des faisceaux de microcanalicules se prolongeant par des microvillosités lesquelles semblent drainer le contenu des vacuoles de sécrétion (pour une interprétation détaillée de cette micrographie, se rapporter à la figure 3).

\section{TAFEL VIII}

\section{Feinbau der Mandibeldrüse von Anthophora}

Авв. 1. - Gesamtansicht einer Sekretzelle. Rechts vom Kern erkennt man den stark entwickelten Ableitungskanal im Cytoplasma und die Quer-oder Schrägschnitte der zahlreichen fingerförmigen Ausstülpungen der Kanalwände, die sich als Mikrovilii ins Cytoplasma erstrecken.

Aвв. 2. - Stark vergnösserter Querschnitt des Kanals innerhalb des Cytoplasmas: Man erkennt die fingerförmigen Ausstiilpungen der Kanalwände, die aus Bündeln zu bestehen scheinen. Diese breiten sich zu Mikrovilli aus, die vermutlich den Sekretinhalt der Vakuolten ableiten (Eingehende Erläuterung hierzu sieche Abb. 3). 
Apidologie, 1970, 1 (3).

Pl. VIII
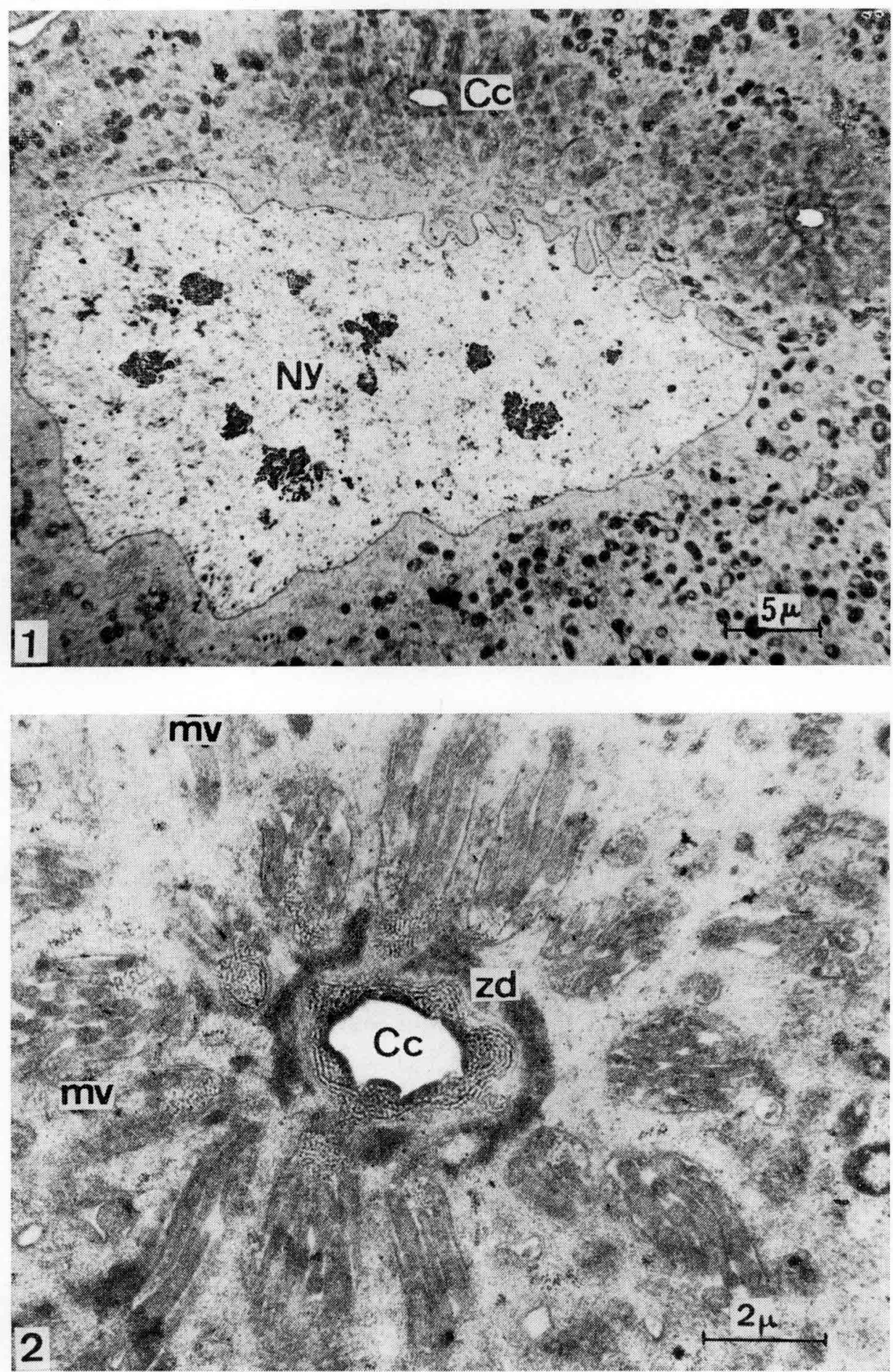

Yvonne HEROIN, Fran ois RAMADE. 


\section{PLANCHE IX}

\section{Ultrastructure de la glande mandibulaire d'Anthophora}

FIG. 1. - Modifications mitochondriales dans une cellule sécrétrice. A côté des mitochondries (mi) d'aspect classique et de forme allongée, on remarque d'autres éléments qui se vacuolisent. Ces modifications ultrastructurales représentent sans doute une phase d'élaboration du sécrétat glandulaire.

Fig. 2. - Autre phase du cycle sécrétoire, le cytoplasme est encombré par de grandes vacuoles sécrétrices, au contenu granulaire, entourées d'une zone moins dense aux électrons.

\section{TAFEL IX}

\section{Feinbau der Mandibeldrüse von Anthophora}

Авв. 1. - Modofizierte Mitochondrien in einer Sekretzelle. Neben Michondrien herkömmlichen Gestalt und von langgestreckter Form (mi) sieht man andere, Vakuolen bildende. Diese Modifikationem im Feinbau stellen zweifellos eine Phase der Sekretbildung der Drüsen dar.

Aвв. 2. - Eine andere Phase des Sekretions-Zyklus. Das Cytoplasma ist mit grossen, Granula enthaltenden Sekretvakuolen angefüllt, die von einer, im Elektronen-Mikroskop weniger dicht erscheinenden Zone, umgeben sind. 
Apidologie, 1970, 1 (3).

Pl. IX
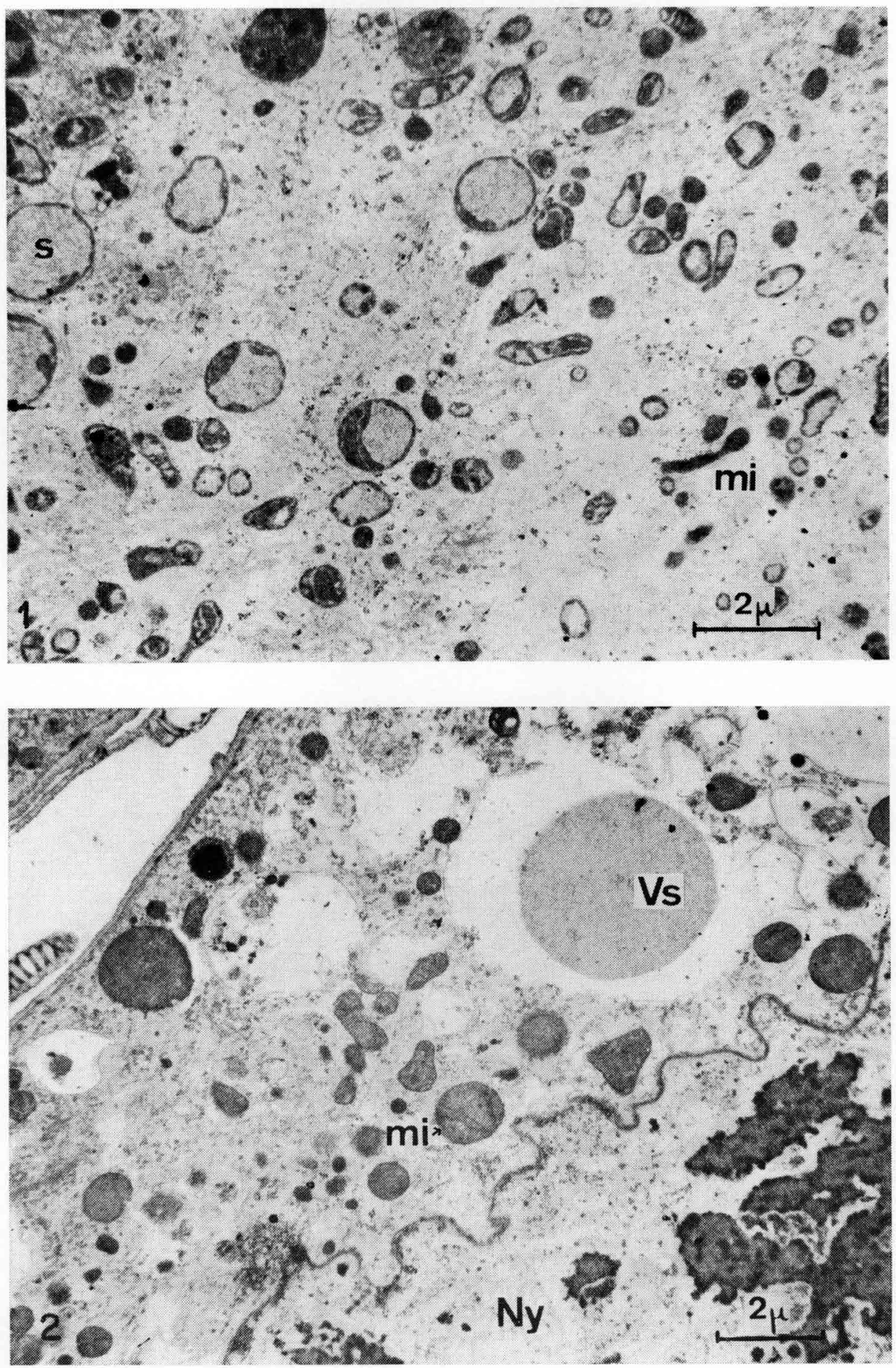

Yvonne HÉROIN, François RAMADE. 